\title{
Bandlike and localized states of extended defects in n-type $\ln _{0.53} G_{0.47}$ As
}

Po-Chun (Brent) Hsu, Eddy Simoen, Clement Merckling, Geert Eneman, Yves Mols, AliReza Alian, Robert Langer, Nadine Collaert, and Marc Heyns

Citation: Journal of Applied Physics 124, 165707 (2018); doi: 10.1063/1.5046827

View online: https://doi.org/10.1063/1.5046827

View Table of Contents: http://aip.scitation.org/toc/jap/124/16

Published by the American Institute of Physics

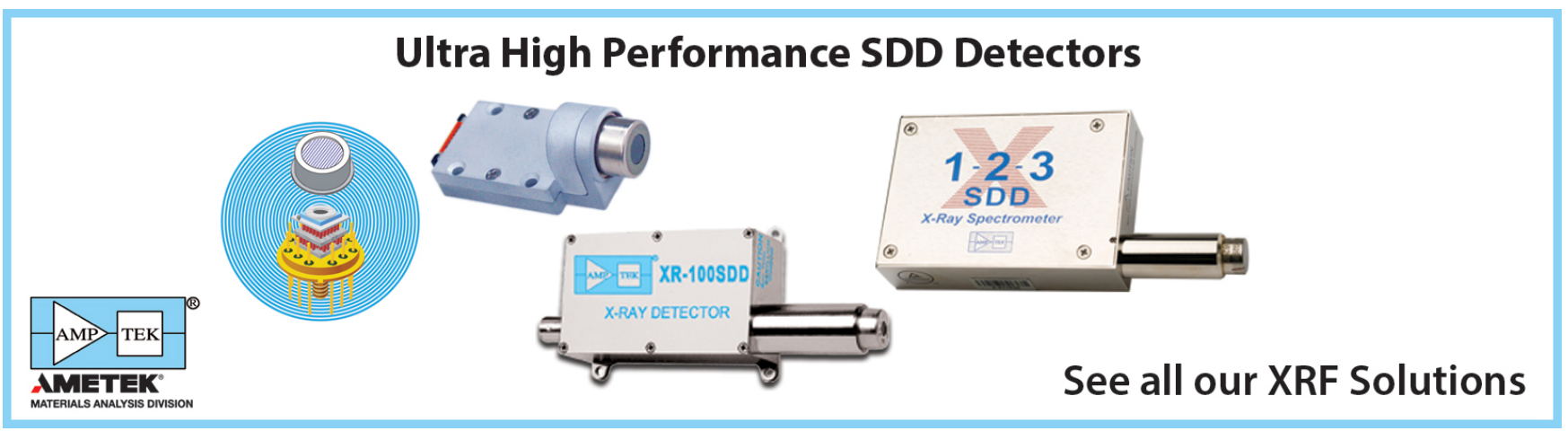




\title{
Bandlike and localized states of extended defects in n-type $\ln _{\mathbf{0 . 5 3}} \mathbf{G a}_{\mathbf{0 . 4 7}} \mathrm{As}$
}

\author{
Po-Chun (Brent) Hsu, ${ }^{1,2}$ Eddy Simoen, ${ }^{1,3}$ Clement Merckling, ${ }^{1}$ Geert Eneman, ${ }^{1}$ Yves Mols, ${ }^{1}$ \\ AliReza Alian, ${ }^{1}$ Robert Langer, ${ }^{1}$ Nadine Collaert, ${ }^{1}$ and Marc Heyns ${ }^{1,2}$ \\ ${ }^{1}$ IMEC, Kapeldreef 75, 3001 Leuven, Belgium \\ ${ }^{2}$ Department of Materials Engineering, KU Leuven, 3001 Leuven, Belgium \\ ${ }^{3}$ Department of Solid State Sciences, Ghent University, 9000 Gent, Belgium
}

(Received 2 July 2018; accepted 7 October 2018; published online 26 October 2018)

\begin{abstract}
$\mathrm{In}_{0.53} \mathrm{Ga}_{0.47} \mathrm{As} \mathrm{p}+\mathrm{n}$ diodes with different densities of extended defects have been analyzed by detailed structural and electrical characterization. The defects have been introduced during MetalOrganic Vapor Phase Epitaxy (MOVPE) growth by using a lattice-mismatched layer on a semi-insulating $\mathrm{InP}$ or GaAs substrate. The residual strain and indium content in the n-type $\mathrm{In}_{0.53} \mathrm{Ga}_{0.47} \mathrm{As}$ layer have been determined by high-resolution X-ray diffraction, showing nearly zero strain and a fixed indium ratio of 0.53 . The deep levels in the layer have been characterized by Deep Level Transient Spectroscopy. The mean value of electron traps at $0.17 \pm 0.03 \mathrm{eV}$ below the conduction band minimum $\mathrm{E}_{\mathrm{C}}$ is assigned to the "localized" states of $\alpha 60^{\circ}$ misfit dislocations; another broad electron trap with mean activation energies between $E_{C}-0.17 \pm 0.01$ and $0.39 \pm 0.04 \mathrm{eV}$, is identified as threading dislocation segments with "band-like" states. A high variation of the pre-exponential factor $K_{T}$ by 7 orders of magnitude is found for the latter when changing the filling pulse time, which can be explained by the coexistence of acceptor-like and donor-like states in the core of split dislocations in III-V materials. Furthermore, two hole traps at $E_{V}+0.42 \pm 0.01$ and $E_{V}+0.26 \pm 0.13$ $\mathrm{eV}$ are related to the double acceptor of the $\mathrm{Ga}(\mathrm{In})$ vacancy $\left(\mathrm{V}_{\mathrm{Ga} / \mathrm{In}}{ }^{3-2-}\right)$ and $60^{\circ} \beta$ misfit dislocations, respectively. Finally, the dislocation climbing mechanism and the evolution of the antisite defects $\mathrm{As}_{\mathrm{Ga} / \mathrm{In}}$ are discussed for $\mathrm{n}$-type $\mathrm{In}_{0.53} \mathrm{Ga}_{0.47} \mathrm{As}$. Published by AIP Publishing.

https://doi.org/10.1063/1.5046827
\end{abstract}

\section{INTRODUCTION}

High saturation velocity and electron mobility make $\mathrm{In}_{0.53} \mathrm{Ga}_{0.47}$ As ternary alloys promising materials for the fabrication of high electron mobility transistors (HEMTs). Likewise, the infrared radiation absorption edge makes the $\mathrm{In}_{0.53} \mathrm{Ga}_{0.47} \mathrm{As} / \mathrm{InP}$ system an attractive candidate for the development of photodetectors. At the same time, there is a strong push to integrate these devices on a silicon substrate, among others, to reduce the production cost and to provide more functionality to the silicon Complementary Metal Oxide Semiconductor (CMOS) platform. The growth of $\mathrm{In}_{0.53} \mathrm{Ga}_{0.47} \mathrm{As}$ on silicon can be achieved by using a strain relaxed buffer (SRB) layer ${ }^{1}$ by aspect ratio trapping (ART) between two $\mathrm{SiO}_{2}$ sidewalls ${ }^{2}$ or by wafer-bonding. ${ }^{3}$

However, these methods inevitably lead to extended defects during the heteroepitaxial growth, because of lattice and thermal mismatch. For example, defects lying in the (111) plane cannot be trapped by the shallow trench isolation (STI) sidewalls in the (1-11) plane. This is one of the major issues in InGaAs-based devices. Thus, understanding the impacts of these crystalline defects on the electrical device performance and reliability is key to their successful development and integration on silicon substrates.

Deep level traps are well-known to degrade the minority carrier recombination lifetime and the off-state leakage (generation lifetime) by the Shockley-Read-Hall (SRH) and Trap-Assisted-Tunneling (TAT) mechanisms. In the case of dislocations, the effects can be amplified and even modified due to the presence of a one-dimensional (1D) density of states (DOS) along their line direction instead of a single energy level. ${ }^{4}$ In past decades, this concept of a 1D DOS, originally introduced to explain the electrical behavior of dislocations in Group IV semiconductors, ${ }^{5,6}$ has also been validated in the InGaAs/GaAs system with band-like HD3 states $^{7}$ (misfit dislocation) and localized ED1 states ${ }^{8,9}\left(\alpha 60^{\circ}\right.$ misfit dislocation).

The distinction between a band-like and localized 1D DOS is based on a study of the evolution of the Deep Level Transient Spectroscopy (DLTS) peak on the filling-pulse duration: $5,6,8$ for a "localized" 1D DOS, the peak maximum of the DLTS amplitude stays at the same temperature and increases over several decades with the logarithm of the filling pulse duration. Moreover, the high temperature sides coincide after the curves are normalized on peak maximum. For "band-like" 1D DOS, the peak maximum of the DLTS amplitude shifts to lower temperatures and the hightemperature sides of the DLTS signal coincide. These features are caused by the different internal equilibrium time $\Gamma_{\mathrm{i}} \cdot{ }^{5}$ If $\Gamma_{\mathrm{i}}$ is much larger than the inverse capture and emission rate $\mathrm{R}_{\mathrm{c}}^{-1}, \mathrm{R}_{\mathrm{e}}^{-1}$, "localized" $1 \mathrm{D}$ DOS will be formed, usually occurring for dislocations "decorated" by structural imperfections like kinks and jogs, by point defect clouds and impurities trapped in the strain field of the dislocation. ${ }^{6}$ On the contrary, for $\Gamma_{\mathrm{i}}<<\mathrm{R}_{\mathrm{c}}^{-1}, \mathrm{R}_{\mathrm{e}}^{-1}$, a "band-like" 1D DOS results, which is formed for so-called "pure dislocations" such as the bounding dislocation at a silicide/silicon interface.

So far, most studies in $\operatorname{In}_{0.53} \mathrm{Ga}_{0.47}$ As focused mainly on native point defects in lattice-matched grown layers on an 
InP substrate. In the past thirty years, most of the understanding of extended defects in $\mathrm{In}_{0.53} \mathrm{Ga}_{0.47} \mathrm{As}$ comes from the $\mathrm{In}_{\mathrm{x}} \mathrm{Ga}_{1-\mathrm{x}} \mathrm{As} / \mathrm{GaAs}$ system, where mainly lower indium contents have been studied $(<30 \%)$. In many cases, little or no information was given on the exact strain state (and hence, band gap $E_{G}$ ) of the studied heteroepitaxial layers. This implies that there is still a lack of data on high indium ratio $(>30 \%)$ layers, with a well-defined strain state. In addition, minority carrier hole traps in n-type $\operatorname{In}_{\mathrm{x}} \mathrm{Ga}_{1-\mathrm{x}} \mathrm{As}$ have been less studied. The goal of this paper is, therefore, to perform a systematic study of the deep-level traps associated with extended defects in n-type $\operatorname{In}_{0.53} \mathrm{Ga}_{0.47} \mathrm{As}$ as a function of their density under nearly zero residual strain.

To reach this goal, $\mathrm{p}+\mathrm{n}$ diodes with well-characterized growth-induced dislocations, generated intentionally by implementing a lattice-mismatch layer, were grown by Metal-Organic Vapor Phase Epitaxy (MOVPE). Residual strain, which changes the bandgap significantly, is minimized and the indium content of the active layer is fixed at 0.53 in order to determine the deep levels of extended defects under the same materials' conditions. Only the defect density and to some extent of defects type change from sample to sample. In this study, we mainly investigate the electrical parameters of extended defects such as $60^{\circ}$ misfit dislocations and threading dislocation segments (interaction between $60^{\circ}$ misfit dislocations). Their impacts on the $\mathrm{p}+\mathrm{n}$ junction performance and generation/recombination lifetime will be reported in another paper.

\section{EXPERIMENTAL DETAILS}

\section{A. Sample preparation}

Five samples labelled in Table I were grown by the Metal-Organic Vapor Phase Epitaxy (MOVPE) technique. The InGaAs heteroepitaxy has been performed in a $300 \mathrm{~mm}$ production AIXTRON Crius MOVPE reactor, equipped with a vertical showerhead injector on $2^{\prime \prime}$ Semi-Insulating InP(001) "epi-ready" wafers from AXT Inc. The group-III precursors were trimethylindium (TMIn), trimethylgallium (TMGa), while the group-V sources are tertiarybutylarsine (TBAs) and tertiarybutylphosphine (TBP). The $\mathrm{Si}, \mathrm{Mg}$, and $\mathrm{Zn}$ doping sources are, respectively, Silane $\left(\mathrm{SiH}_{4}\right)$, Bis(cyclopentadienyl)magnesium $\left(\mathrm{Cp}_{2} \mathrm{Mg}\right)$, and diethylzinc (DEZn). Finally, $\mathrm{H}_{2}$ with a total flow of $48 \mathrm{slm}$ is used as the carrier gas. After sample introduction in the reactor, the InP deoxidation is performed at $600{ }^{\circ} \mathrm{C}$ under TBP for $300 \mathrm{~s}$ at high pressure (480 mbar). Then, the temperature is reduced to the growth temperature of $580^{\circ} \mathrm{C}$, and growth pressure down to 100 mbar for the TBP-to-TBAs transition followed by the InGaAs heteroepitaxy. For the strain relaxed buffer (SRB) layer of sample G_SRB, the grading rate was $3.8 \% \mathrm{misfit} / \mu \mathrm{m}$ at 160 Torr with V/III ratios of 13.6. The thickness of the

TABLE I. List of $n$-type $\mathrm{In}_{0.53} \mathrm{Ga}_{0.47} \mathrm{As}$ parameters derived from SIMS, Hall measurement, capacitance-voltage $(\mathrm{C}-\mathrm{V})$ profiles of the $\mathrm{p}+\mathrm{n}$ diodes and HRXRD measurements. $\mathrm{MD}=60^{\circ}$ Mixed Misfit Dislocation, $\mathrm{PD}=$ Point Defect, $\mathrm{TD}=$ Threading Dislocation segments, and EDDs $=$ Extended Defect Densities.

\begin{tabular}{|c|c|c|c|c|c|}
\hline $\begin{array}{l}\text { Label of } \\
\text { samples }\end{array}$ & $\begin{array}{l}\text { Structure of layers }(\mathrm{p}+/ \mathrm{n}-/ \mathrm{n} \\
\quad+/ \text { substrate }) \pm 0.02(\%)\end{array}$ & $\begin{array}{c}\text { Mean value of FWHM } \boldsymbol{\beta}_{\boldsymbol{\alpha}} \text { in } \\
\{224\} \text { of } n+\text { layer }(\operatorname{arc~sec})\end{array}$ & $\begin{array}{c}\text { EDD from } \\
\text { FWHM } \\
\{224\}\left(\mathrm{cm}^{-2}\right)\end{array}$ & $\begin{array}{l}\text { Defect densities from } \mathrm{e}^{-} \text {trap } \\
\text { DLTS with } \lambda \text {-correction and } \\
\text { filling time of } 1 \mathrm{~ms}\left(\mathrm{~cm}^{-2}\right)\end{array}$ & $\begin{array}{c}\text { Types of extended } \\
\text { defects }\end{array}$ \\
\hline P_In53 & $\begin{array}{c}\mathrm{p}+: 150 \mathrm{~nm} \mathrm{In}_{0.53} \mathrm{Ga}_{0.47} \mathrm{As}(\mathrm{Mg}) \\
\mathrm{n}-:: 850 \mathrm{~nm} \mathrm{In}{ }_{0.53} \mathrm{Ga}_{0.47} \mathrm{As}(\mathrm{Si}) \\
\left(\mathrm{N}_{\mathrm{d}}=1 \sim 3 \times 10^{16} \mathrm{~cm}^{-3}\right) \\
\mathrm{n}+: 250 \mathrm{~nm} \mathrm{In} \mathrm{In}_{\mathbf{0 . 5 3}} \mathrm{Ga}_{\mathbf{0 . 4 7}} \mathrm{As}(\mathrm{Si}) \\
\text { Sub.: SI-InP (Fe) }\end{array}$ & Same as substrate & $<10^{5}$ & (PD1) $5 \times 10^{7}$ & Native growth-in PD \\
\hline P_In47 & 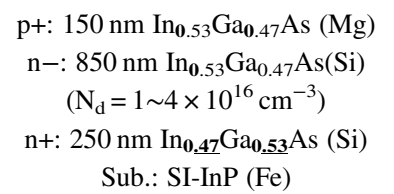 & 54.5 & $5 \times 10^{6}$ & (PD1) $5 \times 10^{7}$ & $\mathrm{PD}, \alpha-\mathrm{MD}$ \\
\hline P_In40 & $\begin{array}{c}\mathrm{p}+: 150 \mathrm{~nm} \mathrm{In}{ }_{0.53} \mathrm{Ga}_{0.47} \mathrm{As}(\mathrm{Mg}) \\
\mathrm{n}-: 850 \mathrm{~nm} \mathrm{In}{ }_{.53} \mathrm{Ga}_{0.47} \mathrm{As}(\mathrm{Si}) \\
\left(\mathrm{N}_{\mathrm{d}}=1 \sim 5 \times 10^{16} \mathrm{~cm}^{-3}\right) \\
\mathrm{n}+: 250 \mathrm{~nm} \mathrm{In} \mathrm{In}_{.40} \mathrm{Ga}_{.60} \mathrm{As}(\mathrm{Si}) \\
\text { Sub.: SI-InP }(\overline{\mathrm{Fe}})\end{array}$ & 238.5 & $9 \times 10^{7}$ & $\begin{array}{l}\text { (E2) } 2 \times 10^{8} \\
\text { (E1) } 1 \times 10^{8}\end{array}$ & $\begin{array}{c}\text { PD, TD, } \alpha-\text { MD rich + } \\
\beta \text {-MD Microcrack }\end{array}$ \\
\hline G_SRB & $\begin{array}{c}\mathrm{p}+: 100 \mathrm{~nm} \mathrm{In}_{0.53} \mathrm{Ga}_{0.47} \mathrm{As}(\mathrm{Zn}) \\
\mathrm{n}-: \mathrm{um} \mathrm{In}_{0.53} \mathrm{Ga}_{0.47} \mathrm{As}(\mathrm{Si})\left(\mathrm{N}_{\mathrm{d}}\right. \\
\left.=0.9 \sim 1 \times 10^{16} \mathrm{~cm}^{-3}\right) \\
\mathrm{n+:} 100 \mathrm{~nm} \mathrm{InP}(\mathrm{Si})+870 \mathrm{~nm} \\
\underline{\text { SRB }}(\mathrm{Si}) \\
\text { Sub.: SI-GaAs }(\mathrm{C})\end{array}$ & 953.3 & $\begin{array}{l}<1 \times 10^{9} \\
\text { Graded }\end{array}$ & $\begin{array}{l}\text { (E2) } 6 \times 10^{8} \\
\text { (E1) } 3 \times 10^{8}\end{array}$ & $\begin{array}{l}\mathrm{PD}, \mathrm{TD}-\text {-rich, } \beta \text {-MD } \\
\text { rich }+\alpha-\mathrm{MD}\end{array}$ \\
\hline P_In13 & $\begin{array}{c}\mathrm{p}+: 150 \mathrm{~nm} \mathrm{In}_{0.53} \mathrm{Ga}_{0.47} \mathrm{As}(\mathrm{Mg}) \\
\mathrm{n}-: 850 \mathrm{~nm} \mathrm{In}_{0.53} \mathrm{Ga}_{0.47} \mathrm{As}(\mathrm{Si}) \\
\left(\mathrm{N}_{\mathrm{d}}=1 \sim 5 \times 10^{16} \mathrm{~cm}^{-3}\right) \\
\mathrm{n+:} 250 \mathrm{~nm} \mathrm{In} \underline{.13}_{\underline{.13}} \mathrm{Ga} . \underline{.87} \mathrm{As}(\mathrm{Si}) \\
\text { Sub.: SI-InP }(\mathrm{Fe})\end{array}$ & 1082 & $2 \times 10^{9}$ & $\begin{array}{l}\text { (E2) } 9 \times 10^{9} \\
\text { (E1) } 7 \times 10^{9}\end{array}$ & $\mathrm{PD}, \mathrm{TD}$-rich, $\alpha, \beta-\mathrm{MD}$ \\
\hline
\end{tabular}


SRB layer was $0.87 \mu \mathrm{m}$ and the growth rates were in the range between 0.24 and $2.13 \mathrm{~nm} / \mathrm{s}$ under a growth temperature of $530^{\circ} \mathrm{C}$.

The layer structure, shown in Fig. 1, consists of $\mathrm{n}+$ $\mathrm{In}_{\mathrm{x}} \mathrm{Ga}_{1-\mathrm{x}} \mathrm{As}$ (Si) with a doping density $N_{d}=2 \times 10^{19} \mathrm{~cm}^{-3}$, which was grown on top of a semi-insulating (SI)-InP (Fe) (001) substrate [SI-GaAs (C) (001) substrate for the G_SRB sample]. For extended defect generation, the indium ratio of the $n+$ layer was varied from 0.13 to 0.53 to create a latticemismatch with the subsequent $n-\operatorname{In}_{0.53} \mathrm{Ga}_{0.47} \mathrm{As}$ (Si) layer. The doping density $\mathrm{N}_{\mathrm{d}}$ of $\mathrm{n}$ - layer varied gradually from $1 \times$ $10^{16} \mathrm{~cm}^{-3}(\mathrm{p}+/ \mathrm{n}-)$ to $5 \times 10^{16} \mathrm{~cm}^{-3}(\mathrm{n}-/ \mathrm{n}+)$ because of upper-diffusion from the $n+$ layer. Finally, $p+\operatorname{In}_{0.53} \mathrm{Ga}_{0.47} \mathrm{As}$ with a doping density $N_{A}=2 \times 10^{18} \mathrm{~cm}^{-3}$ was grown on top of the active layer to form a $\mathrm{p}+\mathrm{n}$ junction. Acceptor dopants were zinc $\left(\mathrm{G}_{-} \mathrm{SRB}\right)$ and magnesium (the other four samples). The thicknesses of all layers in the five samples are shown in Table I.

For the purpose of DLTS, $\mathrm{p}+\mathrm{n}$ junction diodes have been fabricated as follows. After $50 \mathrm{~nm}$ molybdenum (Mo) and $50 \mathrm{~nm}$ aluminum (Al) metal sputtering with a Pfeiffer Spider 630, Ti prime and IX845G photoresist were coated by a spinner system with $4000 \mathrm{rpm}$ for $30 \mathrm{~s}$. Next, mesa etching, stopping in the $n+\operatorname{In}_{x} \mathrm{Ga}_{1-\mathrm{x}}$ As mismatch and ohmic contact layer ( $\mathrm{n}+\mathrm{InP}$ for sample $\left.\mathrm{G} \_\mathrm{SRB}\right)$, was done by wet etching using the following chemistries: $\mathrm{H}_{2} \mathrm{SO}_{4}: \mathrm{H}_{2} \mathrm{O}_{2}: \mathrm{H}_{2} \mathrm{O}=$ 6:18:1000 ( $\operatorname{~} n_{\mathrm{x}} \mathrm{Ga}_{1-\mathrm{x}} \mathrm{As}$ etching), $\mathrm{H}_{2} \mathrm{O}_{2}$ (Mo etching), and OPD5262 (Al, Ti prime, and IX845G etching). Finally, another $5 \mathrm{~nm} \mathrm{Mo}+50 \mathrm{~nm} \mathrm{Al}$ were deposited on top of the $\mathrm{n}$ $+\operatorname{In}_{\mathrm{x}} \mathrm{Ga}_{1-\mathrm{x}}$ As layer ( $\mathrm{n}+\mathrm{InP}$ for sample G_SRB). Sidewall passivation was achieved by depositing a thin $2 \mathrm{~nm} \mathrm{Al}_{2} \mathrm{O}_{3}$ layer by Atomic Layer Deposition (ALD) with a growth temperature of $150{ }^{\circ} \mathrm{C}$. This proved to be important to obtain stable current-voltage (I-V) and DLTS characteristics. The contact diameter of the circular junctions was between 30

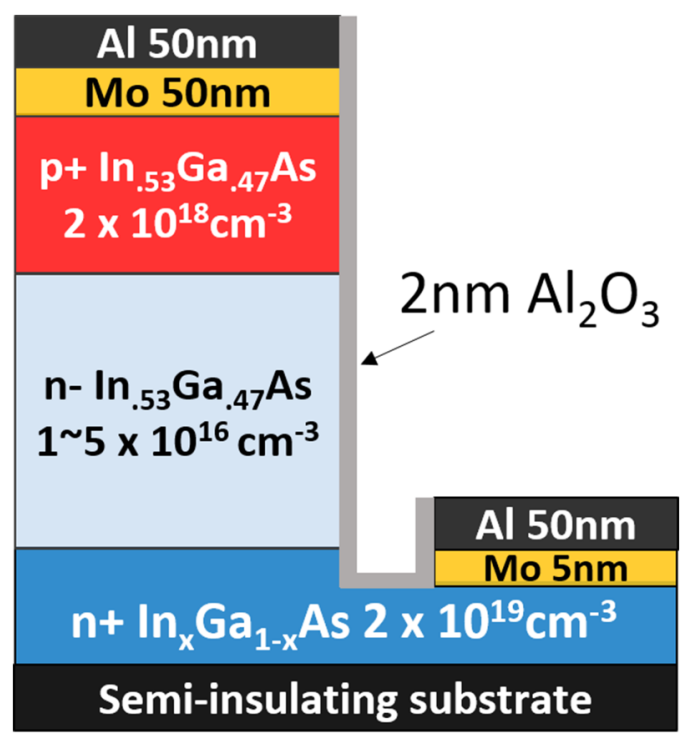

FIG. 1. Schematic cross section of the $\mathrm{p}+\mathrm{In}_{0.53} \mathrm{Ga}_{0.47} \mathrm{As} / \mathrm{n}-\mathrm{In}_{0.53} \mathrm{Ga}_{0.47} \mathrm{As} /$ $\mathrm{n}+\mathrm{In}_{\mathrm{x}} \mathrm{Ga}_{1-\mathrm{x}} \mathrm{As} / \mathrm{SI}$-InP or SI-GaAs substrate junction diode (no scaling) after top-top self-aligned contact fabrication. Note the $n+$ layer of sample G_SRB is $\mathrm{n}+\mathrm{InP}$ on top of an $\operatorname{In}_{\mathrm{x}} \mathrm{Ga}_{1-\mathrm{x}} \mathrm{As}$ strain relaxed buffer layer. The dopant type and layer thicknesses are shown in Table I. and $600 \mu \mathrm{m}$. A schematic of the $\mathrm{p}+\mathrm{n}$ junctions with selfaligned top-top contacts is also given in Fig. 1.

\section{B. Structural and electrical characterization}

The doping density and layer thickness were determined by Secondary Ion Mass Spectrometry (SIMS). The activated dopant concentration was measured by Hall measurements. In addition, Capacitance-Voltage $(\mathrm{C}-\mathrm{V})$ profiles of the $\mathrm{p}+\mathrm{n}$ diodes were taken at a frequency of $1 \mathrm{MHz}$ to confirm the carrier concentration in function of the depletion depth from the junction. The depletion depth at a reverse bias of $5 \mathrm{~V}$ is within the grown layer thickness (up to $600 \mathrm{~nm}$ from the junction), so that the detected deep levels are only within the $\mathrm{n}-\mathrm{In}_{0.53} \mathrm{Ga}_{0.47} \mathrm{As}$ layer of interest. The range of carrier concentrations is summarized in Table I.

The indium content and residual strain were evaluated from High Resolution X-Ray Diffraction (HR-XRD) measurements in a Phillips X'perts system with a Ge (220) 4-crystal monochromator and $\mathrm{Cu}-\mathrm{K} \alpha$ radiation. Reciprocal Space Mappings (RSM) were measured with a triple-axis analyzer crystal in both the (224) and (004) plane. The unit of RSM (rlu) was calculated by using $Q_{x}=$ $R[\cos (\omega)-\cos (2 \theta-\omega)]$ in the in-plane direction, and in the out-of-plane direction by $Q_{y}=R[\sin (\omega)+\sin (2 \theta-\omega)]$, where $\mathrm{R}$ is the radius of the Ewald sphere $=2 \pi / \lambda\left(\AA^{-1}\right), \lambda$ is the wavelength of the incident beam, $\omega$ is the incidence angle, and $\theta$ is the reflection angle. The error calculated from the step size of the RSM, using the range between $0.001^{\circ}$ and $0.01^{\circ}$, giving $\pm 1 \%$ in relaxation and $\pm 0.2 \%$ in indium content.

Deep Level Transient Spectroscopy (DLTS) was performed on $\mathrm{p}+\mathrm{n}$ junction diodes with a Semilab DLS-83D tool using a capacitance bridge operating at $1 \mathrm{MHz}$. The diodes were mounted in a compressed helium cryostat from Lake Shore in vacuum. The temperature $(\mathrm{T})$ can be varied between approximately $10 \mathrm{~K}$ and Room Temperature (RT). During a DLTS measurement, a bias pulse from Vr (quiescent reverse bias) to $\mathrm{Vp}$ was periodically applied to the $\mathrm{p}+$ contact (the $n+$ contact is grounded) to fill the deep levels with majority carriers $(\mathrm{Vp}<0)$ or minority carriers (holes) when $\mathrm{Vp}>0$. The pulse duration is denoted by $\mathrm{Tp}$ and the emission rate window, determined by a lock-in integrator, is represented by Tw. For recording an Arrhenius plot, Tw was changed in the range from $0.1 \mathrm{~s}$ to $5.5 \times 10^{-5} \mathrm{~s}$ and $\mathrm{Tp}$ was fixed at $1 \sim 0.5 \times 10^{-3} \mathrm{~s}$ except for capture kinetic measurements. The sensitivity of the capacitance compensator was $10 \mathrm{pF}$, and the integration time of the lock-in integrator was $3 \mathrm{~s}$.

\section{RESULTS}

\section{A. Structural analysis: Layer strain, defect density, and types}

The strain has a non-negligible impact on the electrical properties of a $\mathrm{p}+\mathrm{n}$ diode. For example, ${ }^{10}$ the intrinsic carrier concentration $n_{i}$ is exponentially varying with the bandgap narrowing due to stress; stress can also impact the energy level and capture cross section of deep-level centers. 
Therefore, to focus only on the electrical parameters of the extended defects, the impact of strain needs to be taken into account or, in other words, this issue needs to be ruled out by measuring on a fully relaxed layer.

Fortunately, the strain in the active layer ( $\mathrm{n}-\mathrm{In}_{0.53} \mathrm{Ga}_{0.47} \mathrm{As}$ ) is relatively small and can be neglected in the further analysis. This is derived from the peak position between the $n+$ layer $\left(\operatorname{In}_{\mathrm{x}} \mathrm{Ga}_{1-\mathrm{x}} \mathrm{As}\right)$ and the substrate $(\mathrm{InP})$ in the asymmetrical (224) RSM, as shown in Fig. 2. In samples P_In47 and P_In40, they have the same $Q_{x}$ value as the substrate, which means most of the $\operatorname{In}_{\mathrm{x}} \mathrm{Ga}_{1-\mathrm{x}} \mathrm{As}$ is pseudomorphically grown and fully strained, i.e., the $n+\mathrm{In}_{\mathrm{x}} \mathrm{Ga}_{1-\mathrm{x}} \mathrm{As}$ layer has the same lattice constant as the InP substrate in the out-of-plane direction, corresponding with the biaxial compressive stress in the in-plane direction. As a result, while growing $\mathrm{n}-\mathrm{In}_{0.53} \mathrm{Ga}_{0.47} \mathrm{As}$ on top of these fully strained layers, the active layer is lattice-matched grown with the nearly zero strain.

On the other hand, in samples G_SRB and P_In13 (Fig. 2), both the $\operatorname{In}_{\mathrm{x}} \mathrm{Ga}_{1-\mathrm{x}} \mathrm{As}$ and the substrate peak align with the inclined dashed line toward the (000) origin and have a large peak broadening in the $\omega$-scan direction (FWHM perpendicular to the fully relaxed line $\sim 1000$ arc sec). It is an evidence when facing the large heteroepitaxial lattice-mismatch $^{11}$ (misfit $\mathrm{f}>2 \%$, depended on layer

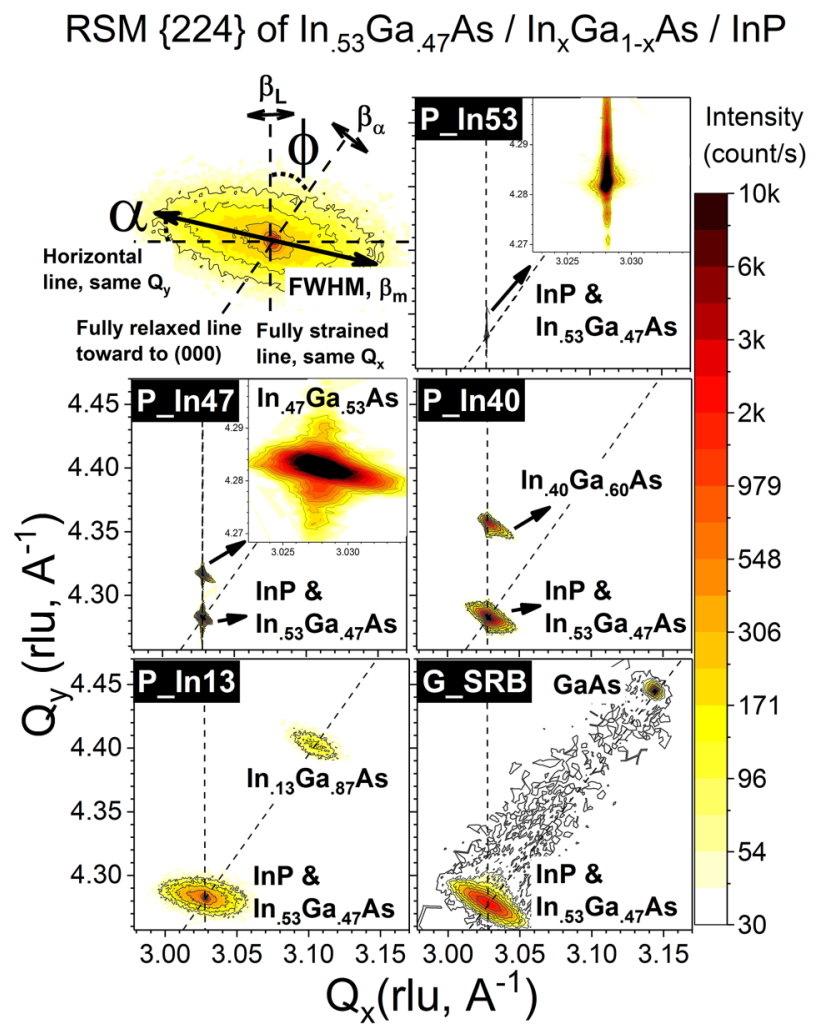

FIG. 2. (224) RSM of five samples with $\mathrm{p}+\mathrm{In}_{0.53} \mathrm{Ga}_{0.47} \mathrm{As} / \mathrm{n}-$ $\mathrm{In}_{0.53} \mathrm{Ga}_{0.47} \mathrm{As} / \mathrm{n}+\mathrm{In}_{\mathrm{x}} \mathrm{Ga}_{1-\mathrm{x}} \mathrm{As} / \mathrm{SI}-\mathrm{InP}$ (SI-GaAs for G_SRB) structure. The indium ratio of the $n+$ layer varies from 0.53 to 0.13 . The inclined dashed line is toward the origin (000). The intensity is on a logarithm scale. $\Phi$ is the angle between the fully strained line and the fully relaxed line, $\alpha$ is the angle between the horizontal line and the broadening direction of the layer. $\beta_{\alpha}, \beta_{\mathrm{L}}$ is the portion of the FWHM broadening contributed by twist (tilt) and the lateral coherence length, respectively. thickness), that the $\mathrm{n}+$ and $\mathrm{n}$ - layers are fully relaxed by the introduction of a huge density of extended defects (mainly misfit and threading dislocations), causing the rotation of the lattice and a consequent broadening of the peak in the $\omega$-scan direction ( $\beta_{\alpha}$, schematic graph in Fig. 2 left top). Besides, the RSM peak of the $\mathrm{n}$ - layer in sample $\mathrm{P}_{-}$In13 is inclined with respect to the fully relaxed line, giving the difference between angle $\alpha$ and $\Phi$ in both RSM224 and RSM2-24 (not shown here) direction. This can be explained by another component of peak broadening: ${ }^{12}$ the lateral coherence length $\beta_{\mathrm{L}}$, coming from the lateral crystallites dimension, affecting the broadening perpendicular to the out-of-plane direction only, proving that sample P_In13 has a mosaic structure with a high defect density.

The FWHM of the $\omega$-scan can yield the threading dislocation density (TDD) due to lattice rotation by tilt or twist. ${ }^{13}$ Although more accurate and visual ways to count the defects density exist, i.e., plan-view Transmission Electron Microscopy (TEM) for high densities $\left(>10^{8} \mathrm{~cm}^{-2}\right)$ and defect etching for low densities $\left(<10^{8} \mathrm{~cm}^{-2}\right)$, these techniques have some limits such as the localized small region or a delicate sample preparation. On the contrary, the defect density determined by HRXRD has the advantage of a non-destructive analysis and is a macro-quantitative feature, which is suitable for our hetero-epitaxial bulk layers.

The FWHM of an $\omega$-scan without curvature, intrinsic, instrumental, and finite size broadening of the sample can be modeled by ${ }^{13}$

$$
\beta_{m}^{2}=\beta_{\varepsilon}^{2}+\beta_{\alpha}^{2}+\beta_{L}^{2},
$$

where $\beta_{m}$ is the measured FWHM, $\beta_{\varepsilon}$ is the broadening due to lattice strain at dislocations (micro-strain), $\beta_{\alpha}$ is the broadening from lattice rotation (tilt or twist) at dislocations, and $\beta_{L}$ is the broadening due to the lateral coherence length. The broadening direction is indicated in Fig. 2 (left-top).

If $\beta_{m}$ is dominated by rotation $\beta_{\alpha}$ and micro-strain of dislocations $\beta_{\mathcal{E}}$, a simple formula for a random distribution of edge-type dislocations has been derived by Kurtz et al. ${ }^{14}$

$$
D_{\beta}=\left(\frac{\beta_{m}}{3 b}\right)^{2},
$$

where $D_{\beta}$ is dislocation density and $b$ is the length of the Burgers vector. Here, the edge component of $60^{\circ}$ mixed misfit dislocations with Burgers vector $=\frac{a}{2}<110>$ is applied, and $\beta_{m}$ is the measured FWHM excluding the $\beta_{L}$ component. Based on Eq. (2), the defect density can be derived for all samples and the results are listed in Table I. Note that due to the mosaic structure in sample P_In13, it is better to evaluate the dislocation density by assuming that the dislocations are located at grain boundaries in consideration of $\beta_{L}$ instead of a random distribution of Eq. (2). For comparison with other samples, we keep using Eq. (2) with $\beta_{\alpha}$ extraction by Eq. (1). ${ }^{12}$

Because it is difficult to deconvolute the $\mathrm{n}-\mathrm{In}_{0.53} \mathrm{Ga}_{0.47} \mathrm{As}$ and InP peak due to their overlap, we only show the $\omega$-FWHM and defect densities of the $n+$ $\mathrm{In}_{\mathrm{x}} \mathrm{Ga}_{1-\mathrm{x}} \mathrm{As}$ layer instead of the active $\mathrm{n}-\mathrm{In}_{0.53} \mathrm{Ga}_{0.47} \mathrm{As}$ 
layer. Therefore, considering the growth mechanism, the defect density of $P_{-} I n 13$ can be underestimated due to a second strain relaxation at the $n-$ layer/n+ layer interface by threading and misfit dislocations. For sample G_SRB, the defect density is most likely overestimated due to a gradual decrease of the defect density from the $n+$ layer/SRB layer interface toward the $\mathrm{p}+$ layer.

Despite the absence of quantification of the $\mathrm{n}-\mathrm{In}_{0.53} \mathrm{Ga}_{0.47} \mathrm{As}$ defect density, the peak broadening of $\mathrm{n}-\mathrm{In}_{0.53} \mathrm{Ga}_{0.47} \mathrm{As}(\mathrm{InP})$ rises roughly proportionally with the increase of the lattice mismatch, which matches the trend of the extended defect densities (EDDs) in the $\mathrm{n}+\mathrm{In}_{\mathrm{x}} \mathrm{Ga}_{1-\mathrm{x}} \mathrm{As}$ layer in Table I.

Moreover, EDDs in the active layer can be evaluated from DLTS. In theory, when the trap density $\mathrm{N}_{\mathrm{T}}$ is much smaller than the doping density $\mathrm{N}_{\mathrm{dop}}\left(\mathrm{N}_{\mathrm{T}}<10^{-3} \times \mathrm{N}_{\mathrm{dop}}\right)$, the trap concentration is approximately proportional to the capacitance transient amplitude. Additionally, considering the free carrier profile at the edge of the depletion region, a so-called $\lambda$-effect correction must be included in the calculation of $\mathrm{N}_{\mathrm{T}}$ $\left(\mathrm{cm}^{-3}\right)$, according to ${ }^{15}$

$$
\frac{N_{T}\left(W_{m}-\lambda_{m}\right)}{N_{d o p}}=\frac{1}{\left(1-\frac{\lambda_{R}}{W_{R}}\right)^{2}-\left(\frac{W_{P}-\lambda_{P}}{W_{R}}\right)^{2}} \frac{2 \Delta C(0)}{C_{R}},
$$

with $W_{m}-\lambda_{m}=0.5\left[\left(W_{R}-\lambda_{R}\right)+\left(W_{P}-\lambda_{P}\right)\right] . \quad \mathrm{C}_{\mathrm{R}}$ is the capacitance at reverse bias, $\Delta C$ is the capacitance transient amplitude, $\mathrm{W}_{\mathrm{P}, \mathrm{R}}$ is the depletion depth under pulse bias or reverse bias $=\frac{A \varepsilon}{C_{P, R}}$, A is the area of the circular mesa junction, $\varepsilon$ is the permittivity of the semiconductor, and $\lambda_{P, R}$ is the distance from the crossing point of the Fermi level $E_{F}$ with the trap level $\mathrm{E}_{\mathrm{T}}$ and the edge of the depletion region, given by $\sqrt{\frac{2 \varepsilon\left(E_{F}-E_{T}\right)}{q^{2} N_{d o p}}}$.

In order to compare the EDD values from the XRD-FWHM method in the unit of $\mathrm{cm}^{-2}$, we multiply the $\mathrm{N}_{\mathrm{T}}$ derived from Eq. (3) by the width of the space charge region, defined by the reverse and pulse bias, which is between the region $\left(W_{R}-\lambda_{R}\right)<\mathrm{z}<\left(W_{P}-\lambda_{P}\right){ }^{15}$ The results are given in Table I, which confirms that the EDDs derived from HRXRD and DLTS amplitude are following the same trends, that is, increase gradually and non-linearly when enlarging the lattice mismatch from P_In53 to P_In13. Note here that Eq. (3) is used to extract the volume trap density for typical point defects. In our case, by assuming a uniform EDD in the probed depleted regions and by neglecting the impacts from alloy broadening, 1D-DOS, and unsaturated traps, all factors do result in an underestimation of the EDD values from the DLTS amplitude. As a result, one should consider that the EDDs from Eq. (3) listed in Table I are mainly qualitative, yielding at best in an order-of-magnitude estimation. Nevertheless, extraction from XRD and DLTS still lead to a similar magnitude of EDD. Additionally, the value in sample P_In47 and P_In53 derived from DLTS are point defect densities (PD1), which is impossible to detect and incomparable with HRXRD.
Finally, it is impossible to judge which specific type of defects (e.g. threading dislocation, misfit dislocation, etc.) dominates the extended-defect densities derived from XRD-FWHM. Because twist and tilt from any type of defects can cause broadening of the XRD peak and then enlarge the density, thus we use the term extended defect densities (EDDs) in the XRD-FWHM part. For the DLTS part, it is possible to identify different traps corresponding to distinct defects by carefully examining data from different sources. Therefore, the exact density of a specific defect can in principle be derived from the corresponding DLTS peak height. It will be discussed in the next paragraph and the DLTS section.

In the zinc-blende structure of III-V materials, two distinct types of $60^{\circ}$ dislocations are gliding on the $\{111\}$ planes and their Burgers vectors are both along $\langle 110\rangle$ directions. ${ }^{16}$ Based on the different dislocation motion and the missing atoms in the most distorted core center, ${ }^{17}$ using the notation of Alexander et al., ${ }^{18}$ an As core glide set dislocation $\mathrm{As}_{(\mathrm{g})}$ and $\mathrm{Ga}$ (or In) core shuffle set dislocation $\mathrm{Ga}$ (or $\mathrm{In})_{(\mathrm{s})}$ are known as $\alpha$ type, vice versa $\mathrm{Ga}(\text { or } \mathrm{In})_{(\mathrm{g})}$ and $\mathrm{As}_{(\mathrm{s})}$ are $\beta$ type. Because $\alpha$ and $\beta$ mixed dislocations have an opposite edge component, one kind relieves tensile stress and the other reduces compressive stress. Thus, the orientation of the dislocation line at the (001) interface will change as well: ${ }^{17}$ (i) under tensile stress, $\alpha$ type yields a misfit dislocation (MD) line in the [1-10] direction and $\beta$ type in [110]. (ii) Under compressive stress, $\alpha$ type results in a [110] MD line and $\beta$ type in [1-10]. In addition, it is well known that a $60^{\circ}$ dislocation is dissociated into a $30^{\circ}$ and a $90^{\circ}$ Shockley partial dislocation to glide efficiently, as reported in detail by Marée et al. ${ }^{19}$ Since this movement is energetically unfavorable for the shuffle set of dislocations, ${ }^{18,20}$ it is generally believed that mobile $60^{\circ}$ dislocations belong to the glide set. Hence, in this work, only glide set $60^{\circ}$ dislocations are considered.

Note that these two types of $60^{\circ}$ mixed misfit dislocations are sometimes indicated as $60^{\circ}$ threading dislocations. In order to be consistent with the literature, we associate these glide set $\mathrm{a} / 2<110>\{111\}$ dislocation type with the $\alpha$ and $\beta 60^{\circ}$ mixed misfit dislocations. All interactions between these $60^{\circ}$ mixed dislocations are considered as threading dislocation segments, for example, kinks, jogs, stacking faults $(\mathrm{SFs})$, pure screw dislocations, and $90^{\circ}$ misfit dislocations. ${ }^{21}$

The dominant type of defects in each sample can be identified from the surface morphology in the Atomic Force Micrographs (AFM) of Fig. 3 and are listed in Table I. In the lattice-matched sample P_In53, no visible EDs are present in the smooth surface (root mean squared roughness $R_{q}=0.554$ $\mathrm{nm}$ ). Therefore, only native grown-in point defects (PDs) are expected to be relevant here.

For sample P_In47 and P_In40, as mentioned in the paragraph on layer strain, the $n+\operatorname{In}_{x} G_{1-x} A s /$ substrate interface is under tensile strain and the subsequent lattice-matched is at the $\mathrm{p} / \mathrm{n}$ - layer. Under this situation, the cross-hatch lines (white dashed lines) located in the [1-10] direction are thought to correspond with $\alpha$ dislocation MD lines with $\mathrm{As}_{(\mathrm{g})}$ core atoms and predominant in both $\mathrm{P}_{-} \mathrm{In} 47$ and P_In40. Beside $\alpha$ dislocations, sample P_In40 also exhibits a small number of $\beta$ dislocation MD lines (white dashed lines 


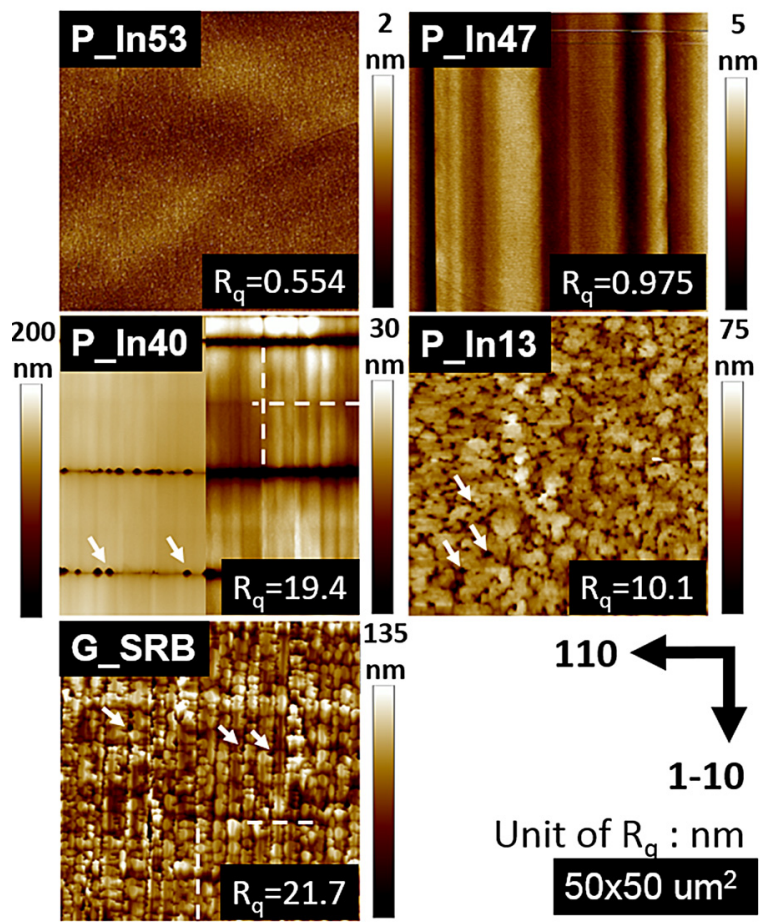

FIG. 3. AFM $50 \times 50 \mu \mathrm{m}^{2}$ image of the $\mathrm{p}+\mathrm{In}_{0.53} \mathrm{Ga}_{0.47} \mathrm{As}(001)$ surface on top of the $n-\operatorname{In}_{0.53} \mathrm{Ga}_{0.47} \mathrm{As} / \mathrm{n}+\mathrm{In}_{\mathrm{x}} \mathrm{Ga}_{1-\mathrm{x}} \mathrm{As} / \mathrm{SI}-\mathrm{InP}$ (SI-GaAs for G_SRB) stack. The scaling bars are on the right side of the graph. The dashed lines in P_In40 and G_SRB indicate the cross-hatch lines generated by misfit dislocations and the arrows point out the pit position coming from threading dislocation arms. $\mathrm{Rq}$ is the root mean squared roughness $(\mathrm{nm})$.

located in [110] direction) and additional defects called "micro-crack" (dark grooves located in [110] direction), in agreement with literature data for the tensile stressed $\mathrm{In}_{1-\mathrm{x}} \mathrm{Ga}_{\mathrm{x}} \mathrm{As} / \mathrm{InP}$ system. $^{22,23}$ The $\beta$ dislocations come from the cross-slip of a $30^{\circ}$ partial dislocation and a $60^{\circ}$ partial dislocation associated with different $\alpha$ dislocations, ${ }^{17}$ when the $\alpha$ dislocation density is high enough. These micro-cracks are generated when the tensile stress exceeds a certain critical level and forms after growth. In addition, because the micro-cracks are located in the (001) plane, ${ }^{23}$ they degrade the diode characteristics dramatically by introducing a conductive shunt path directly from the $\mathrm{p}+$ surface to the InP substrate. Thus, no samples in the $\mathrm{n}+$ layer indium range from 0.40 to 0.13 are used here due to the serious microcrack generation and the extremely leaky $\mathrm{p}+\mathrm{n} \mathrm{I}-\mathrm{V}$ characteristics (not shown here).
For sample P_In13, complete tensile stress in the $\mathrm{n}+$ $\mathrm{In}_{\mathrm{x}} \mathrm{Ga}_{1-\mathrm{x}} \mathrm{As} / \mathrm{InP}$ substrate interface was followed by the compressive stress in the $n-/ n+$ interface, thus no preferential MD lines should be found in this sample. Also, due to the large lattice mismatch $(\mathrm{f}>2 \%),{ }^{11}$ a textured surface morphology with 3-D island growth is expected, causing a rough surface $\left(R_{q}=10.1 \mathrm{~nm}\right)$ shown in Fig. 3. Moreover, many holes (indicated by the white arrows) can be found on the surface, which are the termination spots of the threading arms from both types of $60^{\circ}$ misfit dislocations. These TD holes are also found in P_In40 and G_SRB in particular directions. As a result, the roughness and a huge number of TD holes confirm our interpretation about the residual layer strain, i.e., P_In13 was relaxed by the introduction of a high density of threading dislocations accompanying both types of $60^{\circ}$ misfit dislocations.

The sample G_SRB, on the other hand, tells a totally different story. As shown in Fig. 4, the buffer layer tilt about $1^{\circ}$ only in the [1-10] direction, as already discussed for similar cases in the literature, ${ }^{24-26}$ comes from the different gliding mobility between $\alpha$ and $\beta 60^{\circ}$ dislocations. Generally speaking, G_SRB is compressively stressed during the strained buffer layer growth. Hence, in contrast to the tensile-strained sample, the [1-10] MD line is a $\beta$ dislocation $=\mathrm{Ga}_{(\mathrm{g})}$ and the [110] MD line is an $\alpha$ dislocation $=\mathrm{As}_{(\mathrm{g})}$. During $\mathrm{SRB}$ growth, the $\alpha$ dislocation will elongate fast and then blocks the $\beta$ dislocation propagation due to the different gliding mobility $\left(\mu_{\alpha}>\mu_{\beta}\right),{ }^{27}$ which causes an asymmetrical relaxation and a layer tilt. After SRB growth, more $\beta$ dislocations will be generated to relax the strain, because the residual strain is larger in the [1-10] direction than in the [110] direction. This explains why the cross-hatch line and the presence of the pits of the TD arms are mainly located in the [1-10] ( $\beta$ dislocation) direction and the FWHM of the XRD peak is larger in the [1-10] direction in Figs. 3 and 4, respectively.

Briefly summarizing the structural analysis results, the residual strain in the $n-\operatorname{In}_{0.53} \mathrm{Ga}_{0.47}$ As active layers of interest is relatively small and can be neglected for the electrical analysis. The defect densities estimated by XRD and DLTS show the same trends and reasonable results, which indicate gradually increasing EDDs with larger lattice-mismatch on the $n+/ n-$ layer. For determination of the defect types, based on AFM, XRD, and the literature, sample P_53 is expected to be dominated by grown-in point defects; sample $P_{-}$In47 is rich in $\alpha$ dislocations; sample $P_{-}$In40 has predominant $\alpha$

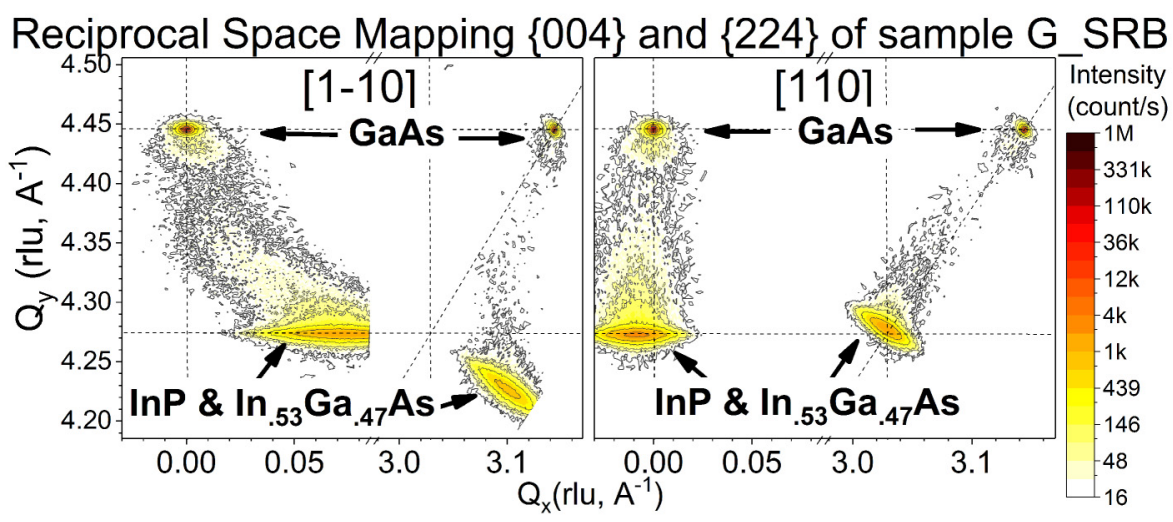

FIG. 4. RSM $\{224\}$ (right side in each graph) and $\{004\}$ (left side in each graph) of sample G_SRB from [110] and [1-10] incident direction. The inclined dashed line of $\{224\}$ is toward the origin (000); the intensity is on a logarithm scale. The tilt of the SRB layer in [1-10] direction is due to the different gliding mobility between $\alpha$ and $\beta 60^{\circ}$ dislocations. 
TABLE II. Electrical states of the traps observed by DLTS in the different $\mathrm{p}+\mathrm{n}$ diodes. $\Delta \mathrm{Ea}=$ "mean" or "apparent" activation energy, $\mathrm{V}_{\mathrm{Ga}}$ and $\mathrm{V}_{\mathrm{In}}=$ gallium and indium vacancy, $\mathrm{Tp}=$ filling pulse time. $\alpha, \beta-\mathrm{MD}=\alpha$ or $\beta$ type $60^{\circ}$ misfit dislocation

\begin{tabular}{|c|c|c|c|c|}
\hline $\begin{array}{l}\text { Name of } \\
\text { traps }\end{array}$ & Identification of traps & $\begin{array}{c}\Delta \mathrm{Ea}(\mathrm{eV}) \\
\text { for } \mathrm{e}^{-}=\mathrm{E}_{\mathrm{C}}-\mathrm{E}_{\mathrm{T}} \\
\text { for } \mathrm{h}^{+}=\mathrm{E}_{\mathrm{T}}-\mathrm{E}_{\mathrm{V}}\end{array}$ & $\begin{array}{l}\text { Pre-exponential factor } \mathrm{K}_{\mathrm{T}}\left(\mathrm{sT}^{2}\right) \\
\text { and capture cross section }\left(\mathrm{cm}^{2}\right)\end{array}$ & Remark \\
\hline PD1 & 44 & $\mathrm{e}^{-}: 0.16 \pm 0.02$ & $\begin{aligned} \mathrm{K}_{\mathrm{T}}: 7.4 \times 10^{-2} \\
\sigma_{\mathrm{n}}: 1 \times 10^{-19}\end{aligned}$ & Point defects \\
\hline PD2 & $\mathrm{V}_{\mathrm{Ga}}^{-2 /-3}$ or $\mathrm{V}_{\mathrm{In}}^{-2 /-3}$ & $\mathrm{~h}^{+}: 0.42 \pm 0.01$ & $\begin{array}{c}\mathrm{K}_{\mathrm{T}}: 6.8 \times 10^{-9} \\
\sigma_{\mathrm{p}}: 1 \times 10^{-13}\end{array}$ & Attractive $\mathrm{h}^{+}$center point defects \\
\hline E1 & $\begin{array}{c}\text { ED1 }=\boldsymbol{\alpha} \text {-MD } \\
\text { with localized states }\end{array}$ & $\mathrm{e}^{-}: 0.17 \pm 0.03$ & $\begin{array}{c}(\mathrm{Tp}=0.05 \mu \mathrm{s} \rightarrow 1 \mathrm{~ms}) \\
\mathrm{K}_{\mathrm{T}}: 1.1 \times 10^{-7} \rightarrow 2.5 \times 10^{-5} \\
\sigma_{\mathrm{n}}: 7 \times 10^{-14} \rightarrow 3 \times 10^{-16}\end{array}$ & Extended defects, $\mathrm{K}_{\mathrm{T}}$ vary with Tp, Fig. 9 \\
\hline E2 & $\begin{array}{l}\text { Segments of threading dislocation with } \\
\text { bandlike states }\end{array}$ & $\begin{array}{c}(\mathrm{Tp}=1 \mu \mathrm{s} \rightarrow 1 \mathrm{~ms}) \\
\mathrm{e}^{-}: 0.39 \pm 0.04 \rightarrow \\
0.17 \pm 0.01\end{array}$ & $\begin{aligned}(\mathrm{Tp}=1 \mu \mathrm{s} & \rightarrow 1 \mathrm{~ms}) \\
\mathrm{K}_{\mathrm{T}}: 7.5 \times 10^{-7} & \rightarrow 1.8 \times 10^{-1} \\
\sigma_{\mathrm{n}}: 1 \times 10^{-14} & \rightarrow 4 \times 10^{-20}\end{aligned}$ & $\begin{array}{c}\text { Extended defects, Both trap levels and } \mathrm{K}_{\mathrm{T}} \\
\text { vary with Tp, Fig. } 9\end{array}$ \\
\hline H1 & & $\mathrm{h}^{+}: 0.46 \pm 0.03$ & $\begin{array}{c}\mathrm{K}_{\mathrm{T}}: 3.4 \times 10^{-6} \\
\sigma_{\mathrm{p}}: 2 \times 10^{-16}\end{array}$ & \\
\hline $\mathrm{H} 2$ & HD1 = ß-MD & $h^{+}: 0.26 \pm 0.13$ & $\begin{array}{r}\mathrm{K}_{\mathrm{T}}: 1.7 \times 10^{-7} \\
\sigma_{\mathrm{p}}: 4 \times 10^{-15}\end{array}$ & \\
\hline
\end{tabular}

dislocations plus some $\beta$-dislocations and micro-cracks; sample G_SRB, on the other hand, will have more $\beta$ than $\alpha$ dislocations and P_In13 will be mainly dominated by the threading segments, $\alpha$ and $\beta 60^{\circ}$ misfit dislocations.

\section{B. DLTS analysis}

Several issues exist when applying DLTS on $\mathrm{p}+\mathrm{n}$ $\mathrm{In}_{0.53} \mathrm{Ga}_{0.47} \mathrm{As}$. Frist, due to the relatively small bandgap of $\sim 0.74 \mathrm{eV}$, it is possible that traps close to mid-gap or the valence band (below mid-gap) can capture electrons and emit them to the conduction band (vice versa for holes). Whether capturing majority or minority carriers depends on the difference between the occupation probability integration of the final occupied state $f_{t, \text { capture }}$ after the capture state and the final empty state $f_{t, e m i s s i o n}$ after the emission state.

Second, because of the non-exponential carrier filling behavior of semiconductor alloys in ternary materials ${ }^{28}$ and extended defects, ${ }^{29}$ the peak shape becomes much broadened. Therefore, a significant peak overlapping is expected, jeopardizing the analysis, especially with minority carrier injection under forward bias in $\mathrm{p}+\mathrm{n}$ junctions. In this paper, to prevent such a complicated situation, we only calculated EDDs, capture kinetics (Tp varying scan), activation energy $\left(\Delta \mathrm{E}_{\mathrm{T}}\right)$, pre-exponential factor $\left(\mathrm{K}_{\mathrm{T}}\right)$, and capture crosssection $\left(\sigma_{\mathrm{n}, \mathrm{p}}\right)$ in the absence of minority carrier injection, except for the study of the hole traps.

Finally, in order to determine the peak position and amplitude of all peaks including EDs and PDs, a Gaussian curve fitting is applied with the base line equal to zero, followed by the EDDs calculation from Eq. (3) and the electrical parameter extraction $\left(\Delta \mathrm{E}_{\mathrm{T}}, \sigma\right.$, and $\left.\mathrm{K}_{\mathrm{T}}\right)$ from conventional Arrhenius plots including error bar (Table II). As a result, for the case of extended defects (E1, E2, H1, and $\mathrm{H} 2)$, the $\Delta \mathrm{E}_{\mathrm{T}}$ and $\sigma$ are "apparent" or "mean" values instead of "real" electrical states of 1D-DOS. These "apparent" values represent the sum over the occupation of all states $\mathrm{N}_{\mathrm{T}}(\mathrm{E})$ which includes the mechanism of the internal carrier exchange, the lattice relaxation, and the electrostatic potential barrier. Although so far there is no clear connection between these apparent parameters and real states, ${ }^{41}$ the apparent parameters are still comparable to distinguish the type of defects (see discussion in Sec. IV)

DLTS spectra of the five samples under conditions of majority carrier capture are shown in Fig. 5. Using a reversebias pulse, only electron traps are expected to be filled by electrons from the n-type $\operatorname{In}_{0.53} \mathrm{Ga}_{0.47} \mathrm{As}$ region. Comparing the activation energy $\Delta \mathrm{E}_{\mathrm{T}}$ and pre-exponential factor $\mathrm{K}_{\mathrm{T}}$ derived from an Arrhenius plot:

$$
\tau_{n} T^{2}=K_{T} \exp \left(\frac{\Delta E_{T}}{k T}\right),
$$

where $\tau_{\mathrm{n}}$ is emission time(s). In Fig. 5, three main types of electron traps E1, E2, and PD1 can be distinguished. PD1 is only observed in the low EDD samples (P_In53), while E1 and E2 emerge in the diodes with higher EDD.

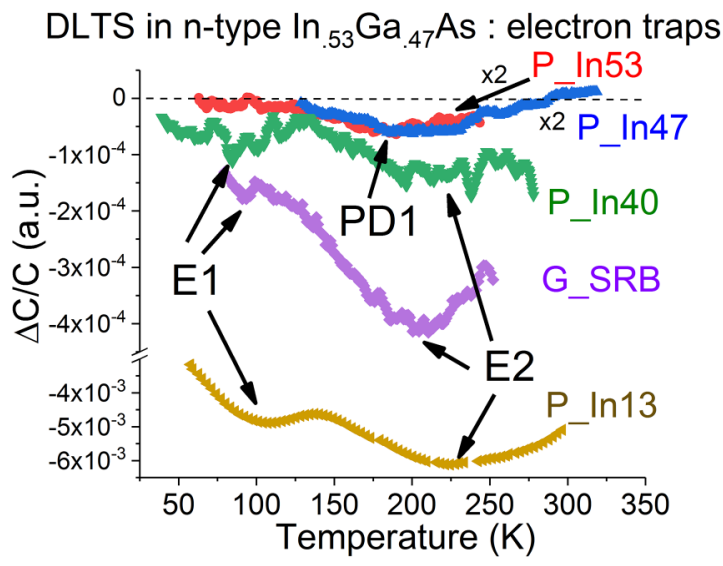

FIG. 5. Majority-carrier DLTS spectra of n-type $\mathrm{In}_{0.53} \mathrm{Ga}_{0.47} \mathrm{As}$ with different EDDs. The reverse bias $\mathrm{Vr}$ is $-5 \mathrm{~V},-5 \mathrm{~V},-1.8 \mathrm{~V},-2.5 \mathrm{~V}$, and $-2 \mathrm{~V}$ from P_In53(top) to P_In13(bottom), respectively. The pulse bias is $-0.5 \mathrm{~V}$, except for P_In 40 where it is $-0.2 \mathrm{~V}$. The lock-in window is $51.2 \mathrm{~ms}$ and the pulse duration is $0.5 \mathrm{~ms}$. Three electron traps E1, E2, and PD1 are revealed. 
On the other hand, when applying a bias pulse to forward voltage to the diode, hole injection occurs, which can fill hole traps in the $n$ layer close to the $p+n$ junction, together with electron traps deeper in the depletion region. ${ }^{30}$ The spectra with hole injection are shown in Fig. 6. Except the E1 and E2 electron traps already shown in Fig. 5, three new hole traps H1, H2, and PD2 are found. The activation energies, pre-exponential factors $\mathrm{K}_{\mathrm{T}}$, and the capture cross section $\sigma_{\mathrm{n}, \mathrm{p}}$ found in this work are listed in Table II. Note that $\sigma_{\mathrm{n}, \mathrm{p}}$ is derived from $\mathrm{K}_{\mathrm{T}}$ by

$$
\begin{gathered}
\text { For electrons : } K_{T}=\left(\frac{g_{n}}{N_{c} \sigma_{n} V_{t h n}}\right) T^{2}, \\
\text { For holes }: K_{T}=\left(\frac{g_{p}}{N_{V} \sigma_{p} V_{t h p}}\right) T^{2},
\end{gathered}
$$

where $g_{n, p}$ is the ratio of the degeneracy in the initial bound state and the final free state, $\mathrm{N}_{\mathrm{C}, \mathrm{V}}$ is the effective density of states in the conduction or valence band, and $\mathrm{V}_{\text {thn,thp }}$ is the thermal velocity for electrons or holes.

Note in Fig. 5 that the assignment of the negative peaks located at $100 \mathrm{~K}$ and $210 \mathrm{~K}$ for different samples to the same electron traps E1 and E2, respectively, is mainly based on the same or similar apparent $\Delta \mathrm{E}_{\mathrm{T}}$ and $\mathrm{K}_{\mathrm{T}}$ derived from Arrhenius plots; the same applies for $\mathrm{H} 1$ at $250 \mathrm{~K}$ in Fig. 6. However, due to the broad feature of the peaks, it is still possible that these peaks belong to a different kind of defects considering that the broadening of the peaks change from sample to sample, giving a clue that either electrical states of the 1D-DOS or the origin of the traps vary as well. Nevertheless, this paper will still assign these traps with the same source in different samples.

The next step is to figure out whether the deep levels behave as PDs or as EDs. This can be achieved by measuring the evolution of the DLTS peak amplitude (and shape) with

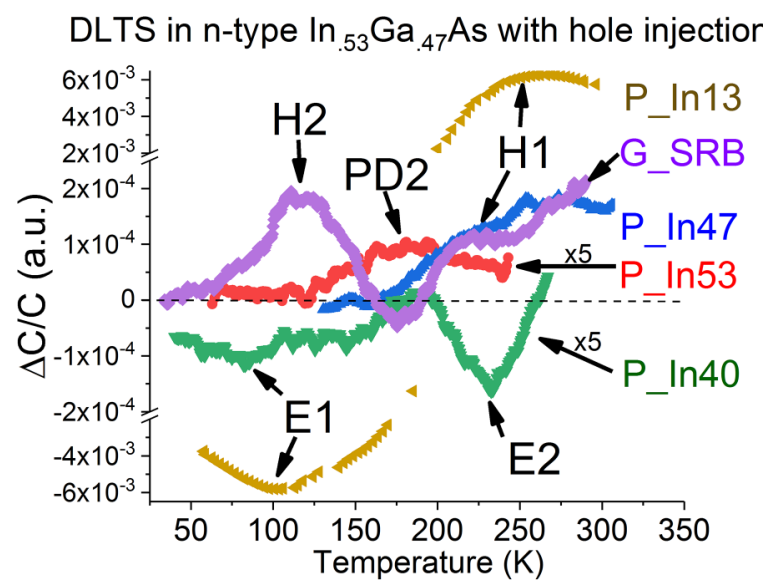

FIG. 6. DLTS spectra of n-type $\mathrm{In}_{0.53} \mathrm{Ga}_{0.47} \mathrm{As}$ with minority carrier injection and different EDDs. The negative DLTS signals $\Delta \mathrm{C} / \mathrm{C}$ represent electron traps and positive $\triangle \mathrm{C} / \mathrm{C}$ correspond with hole traps. The reverse bias $\mathrm{Vr}$ is $-0.5 \mathrm{~V}$. The pulse bias is $0.2 \mathrm{~V}$ except for P_In13 and P_In53 where it is $0.3 \mathrm{~V}$. The lock-in window is $51.2 \mathrm{~ms}$ and the pulse duration is $0.5 \mathrm{~ms}$. Due to the hole injection by applying a pulse voltage into forward bias, three new hole traps $\mathrm{H} 1, \mathrm{H} 2$ and PD2 are revealed. the filling-pulse duration (Fig. 7). ${ }^{29}$ PD1 shows the conventional exponential filling behavior of a point defect with a saturation of the amplitude around $1 \mu \mathrm{s}$. On the other hand, E1 and E2 present a slow filling behavior more or less proportional to $\ln (\mathrm{Tp})$ over many decades. This behavior points to an extended defect origin and can be explained by considering the existence of a potential barrier around the 1D-DOS, which increases with increasing electron occupation.

Combining with the results from the structural analysis, the levels PD1 and PD2 are found in sample P_In53, which contain a low EDD and show point-defect trap filling kinetics. So, it is reasonable to assume that the $\mathrm{P}_{-}$In53 diodes are governed by grown-in PDs. Besides, E2 and PD1 are overlapping in the rest of the samples (Fig. 5) at $\mathrm{T}=200 \mathrm{~K}$ so that it is difficult to detect PD1 in the higher EDDs samples. Moreover, PD2 totally disappears in the other samples in Fig. 6. The reason is still unclear; one possibility being that this type of point defect can be consumed in the formation of MDs or TDs. Another possibility is that the PD2 level at $\mathrm{E}_{\mathrm{V}}+0.42 \mathrm{eV}$ can also communicate with the conduction band, which can give rise to a negligible trap occupation during an injection pulse, by immediate recombination of a captured hole with a subsequent electron capture.

Figure 8 shows the DLTS spectra of E1 and E2 in function of the filling time duration, where E1 matches the criteria of "localized states" extended defects. That is, the peak maximum of the DLTS amplitude stays at the same temperature. In addition, due to the overlap between the E1 and E2 peak, the high temperature side of the peaks does not coincide after normalization. To further investigate the mean value of activation energy and pre-exponential factor $\mathrm{K}_{\mathrm{T}}$ in each captured state, a series of Arrhenius plots based on the electron emission rate Eq. (4) are measured and shown in Fig. 9. The pre-exponential factors $K_{T}$ of E1, derived from the intercept of a linear fit, slowly increase from $1.1 \times 10^{-7}$ to $2.5 \times 10^{-5} \mathrm{sK}^{2}$, when the pulse duration increases from $0.05 \mu$ s to $1 \mathrm{~ms}$, with a fixed mean value of trap levels at $\mathrm{E}_{\mathrm{C}}-0.17 \pm 0.03 \mathrm{eV}$.

On the other hand, E2 shows a behavior similar as for "band-like states" spectra but the peak maximum shifts to a

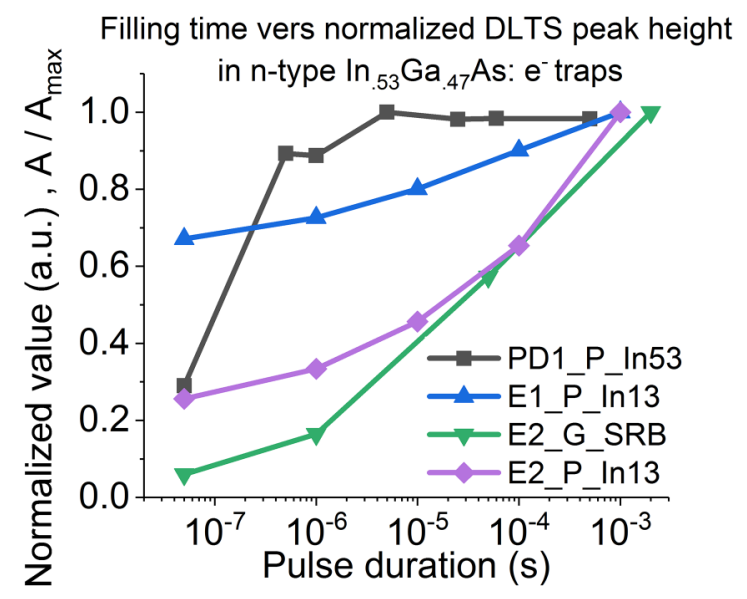

FIG. 7. Filling-pulse duration measurement for traps E1, E2, and PD1 without minority carrier injection. The unit in the y-axis is the magnitude of the peak at each pulse time divided by its maximum value at the longest pulse. The pulse duration varies from $0.05 \mu$ s to $1 \mathrm{~ms}$. 

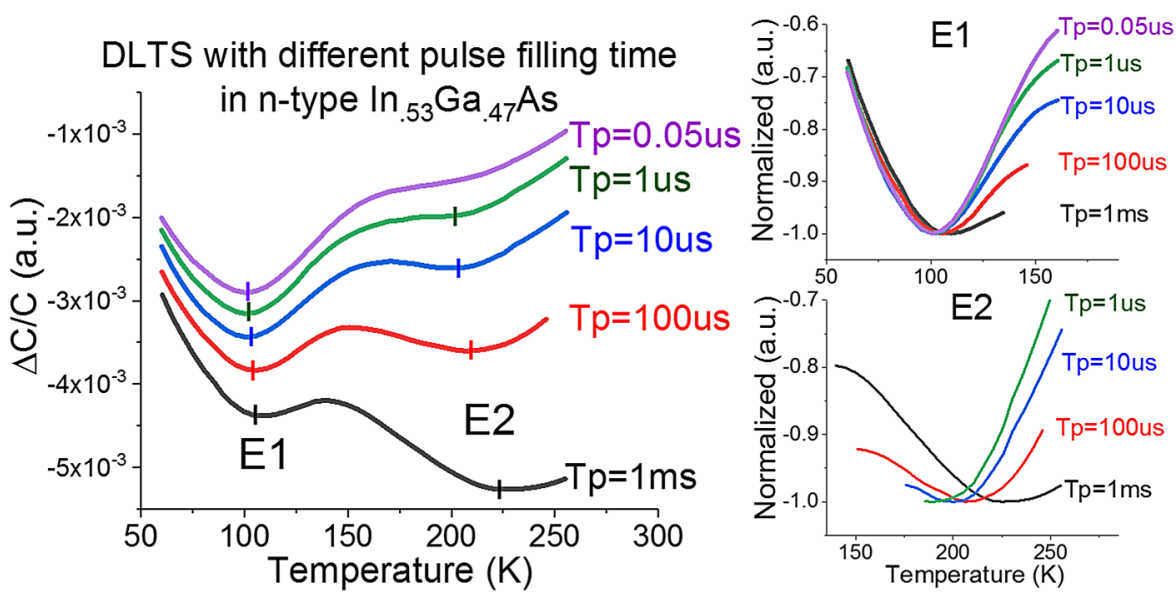

FIG. 8. DLTS spectra for different filling-pulse durations for electron traps E1, E2 without minority carrier injection. Normalized scale graphs of traps E1 and E2, plotting by the value divided by the magnitude of the peak at each pulse, are shown in the right top and bottom, respectively. The lock-in windows $\mathrm{Tw}$ is $51.2 \mathrm{~ms}$, the reverse bias is $-2 \mathrm{~V}$ and the pulse bias is $-0.5 \mathrm{~V}$.

higher instead of a lower temperature when the filling pulse duration increases (Fig. 8). This is contradictory to the criteria for band-like states. However, when comparing the Arrhenius plots for different Tp from $1 \mu$ s to $1 \mathrm{~ms}$ in Fig. 9, the mean value of activation energy becomes smaller with longer pulse duration, while the $\mathrm{K}_{\mathrm{T}}$ dramatically increases from $7.5 \times 10^{-7}$ to $0.18 \mathrm{sK}^{2}$. As a result, this enormous, seven-order $\mathrm{K}_{\mathrm{T}}$ changing causes a shift in the emission rate Eq. (4) to higher temperature although $E_{c}-E_{T}$ becomes smaller. In addition, the E2 Arrhenius-plot shows the "band-like" signature of two different regions similar to the observations of Hedemann et al. ${ }^{41}$ and Grillot et al., ${ }^{31}$ namely, a relatively paralleled shift of the Arrhenius lines at lower $\mathrm{Tp}(<100 \mu \mathrm{s})$ and a strong slope change under higher $\mathrm{Tp}>(100 \mu \mathrm{s})$. Therefore, E2 is still identified with bandlike states.

\section{DISCUSSION}

In summary, PD1, PD2, E1, and E2 have been identified as two point defects, a localized state and a band-like state of EDs in n-type $\mathrm{In}_{0.53} \mathrm{Ga}_{0.47} \mathrm{As}$, respectively. In order to further support the assignment of E1 and E2, a comparison between

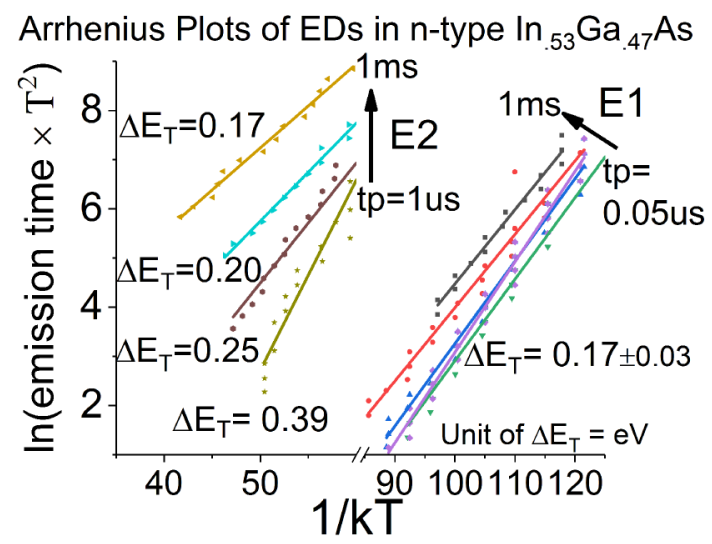

FIG. 9. Arrhenius plot corresponding with E1 and E2. The pre-exponential factor $\mathrm{K}_{\mathrm{T}}$ of $\mathrm{E} 1$ increase from $1.1 \times 10^{-7}, 1.2 \times 10^{-6}, 1.2 \times 10^{-6}, 1.8 \times 10^{-5}$, to $2.5 \times 10^{-5} \mathrm{sK}^{2}$ when filling pulse duration $\mathrm{Tp}$ varies from $0.05 \mu \mathrm{s}, 1 \mu \mathrm{s}$, $10 \mu \mathrm{s}, 100 \mu \mathrm{s}$ to $1 \mathrm{~ms}$, respectively. The error bar of activation energy in E2 is 0.01 to $0.03 \mathrm{eV}$. On the other hand, the $\mathrm{K}_{\mathrm{T}}$ of $\mathrm{E} 2$ change from $7.5 \times 10^{-7}$, $7.5 \times 10^{-4}, 1.5 \times 10^{-2}$ to $0.18 \mathrm{sK}^{2}$ when $\mathrm{Tp}$ varies from $1 \mu \mathrm{s}, 10 \mu \mathrm{s}, 100 \mu \mathrm{s}$ to $1 \mathrm{~ms}$, respectively. available literature on the activation energy of dislocations in the $\operatorname{In}_{\mathrm{x}} \mathrm{Ga}_{1-\mathrm{x}} \mathrm{As} / \mathrm{GaAs}$ or $\operatorname{In}_{\mathrm{x}} \mathrm{Ga}_{1-\mathrm{x}} \mathrm{As} / \mathrm{InP}$ system, and the current data are represented in Fig. 10. The electron trap ED1 at $\mathrm{E}_{\mathrm{C}}-0.7 \mathrm{eV}$ has been assigned to the $\alpha 60^{\circ}$ misfit dislocation in $\mathrm{GaAs}^{37}$ and later confirmed in $\mathrm{In}_{\mathrm{x}} \mathrm{Ga}_{1-\mathrm{x}} \mathrm{As}$ with $\mathrm{x}$ between $0 \%$ and 20\%. ${ }^{7-9,34,38}$ According to Fig. 10, the ED1 level shifts closer to the conduction band edge with increasing indium content, also moving slightly closer to the valence band edge ( 0 energy level in Fig. 10). In $\operatorname{In}_{x} \mathrm{Ga}_{1-\mathrm{x}} \mathrm{As}$ with $x$ equal to $0.02,0.077$, and 0.085 , the "localized" nature of the ED1 states has been recognized, ${ }^{7-9}$ while no "bandlike" dislocation states have so far been reported for electron traps in $\operatorname{In}_{\mathrm{x}} \mathrm{Ga}_{1-\mathrm{x}} \mathrm{As}$.

Note that in the early DLTS studies, usually a single activation energy corresponding with a certain peak maximum position has been reported. As shown here, it is important to study the Arrhenius plot in function of Tp if the states have a band-like character. Also, it is better to present the pre-exponential factor $\mathrm{K}_{\mathrm{T}}$ instead of the capture cross section derived from Eq. (5), ${ }^{40,41}$ which is used to analyze the electrical parameters in point defects. Nevertheless, in order to be consistent with the literature, we will associate $\mathrm{K}_{\mathrm{T}}$ with $\sigma_{\mathrm{n}}$ and present a single level on the extended defects in the figure. In addition, in most previous works little details

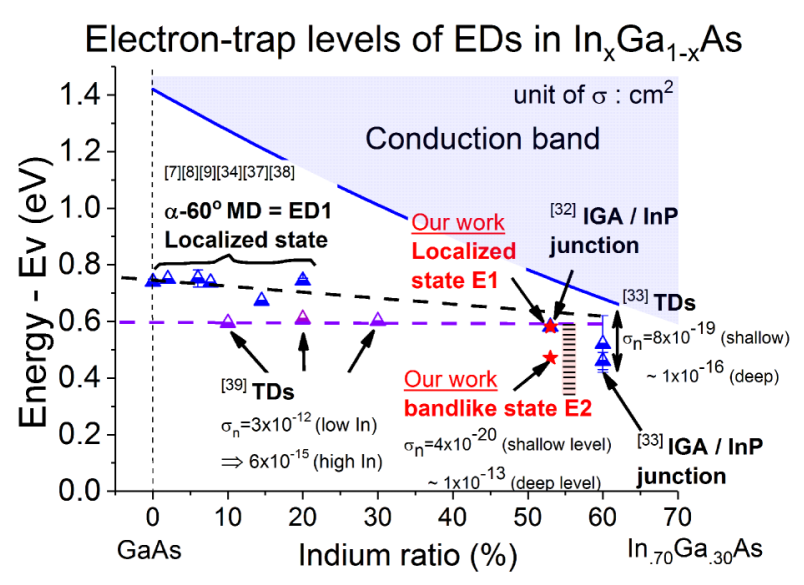

FIG. 10. Literature data for the electron traps in $\operatorname{In}_{\mathrm{x}} \mathrm{Ga}_{1-\mathrm{x}} \mathrm{As}$ corresponding to specific extended defects. The data reported here for E1 and E2 are also included. The y-axis corresponds with the measured activation energy with respect to the valence band maximum. 
were given on the strain state of the studied layers-most likely they were fully relaxed, with negligible residual strain.

Extrapolating the trend of the localized ED1 level in Fig. 10 (black dashed line) results in an activation energy of $0.12 \mathrm{eV}$ in $\mathrm{In}_{.53} \mathrm{Ga}_{0.47}$ As below the conduction band, which is in reasonable agreement with our localized states E1 at $E_{C^{-}}-0.17 \pm 0.03$. The small energy deviation of $0.05 \mathrm{eV}$ might come from the rearrangement of "decorated" elements (point defects, impurities, or reconfiguration of jogs and kinks) within the dislocations by elastic interaction or fluctuating electric fields, ${ }^{40}$ giving rise to a non-monotonous activation energy distribution. This dispersion also leads an unsolved disagreement with simulation results of localized states at the low temperature side. ${ }^{40,41}$ If considering this discrepancy, the localized E1 can be connected with ED1.

Along the same lines, one can compare the E2 band with the data reported for threading dislocations in the composition range from 0.1 to $0.3{ }^{39}$ It was concluded that the corresponding electron traps were pinned to the valence band (Fig. 10, purple dashed line). The electron capture cross section was found to vary from $3 \times 10^{-12}$ to $6 \times 10^{-15} \mathrm{~cm}^{2}$ with increasing indium content. Extrapolating this horizontal dashed line to 53\% indium, we arrive at the top of the E2 band at $E_{C}-0.17 \pm 0.02$, with a smaller electron capture cross section of $4 \times 10^{-20} \mathrm{~cm}^{2}$, confirming the trend of reducing $\sigma_{\mathrm{n}}$ for higher indium content. Because the previous measurements have been performed with filling times of $50 \mu \mathrm{s}$, in "band-like" states it is reasonable to compare with the similar filling time of $100 \mu \mathrm{s}$ in E2 (Fig. 9), giving the energy level $\mathrm{E}_{\mathrm{C}^{-}}-0.20 \pm 0.01$ and electron capture cross section of $5 \times 10^{-19} \mathrm{~cm}^{2}$. Although the energy level does not perfectly match (difference $\sim 0.03 \mathrm{eV}$ ), it still agrees that most of the DOS is filled by electrons with a filling time of $100 \mu \mathrm{s}$. Nevertheless, as mentioned before, no observation of "bandlike" states in $\mathrm{In}_{\mathrm{x}} \mathrm{Ga}_{1-\mathrm{x}}$ As was reported in previous work.

On the other hand, a series of electron traps lying between $\mathrm{E}_{\mathrm{C}}-0.06 \mathrm{eV}$ and $0.26 \mathrm{eV}$ (Fig. 10, for $60 \%$ indium) has been observed before by admittance spectroscopy in InP/ $\mathrm{In}_{0.60} \mathrm{Ga}_{0.40} \mathrm{As} / \mathrm{InP}$ heterostructure photodiodes grown by Low Pressure Metal-Organic Chemical Vapor Deposition (LP-MOCVD). ${ }^{33}$ The corresponding $\operatorname{In}_{0.6} \mathrm{Ga}_{0.4} \mathrm{As}$ layers showed $10 \%$ residual strain with a large density of grown-in dislocations. The variation in electron trap activation energy was derived by combining data from different diodes after fabrication. It was claimed that this broad range of activation energies could come from the additional thermal budget after epitaxy, yielding a movement of the grown-in threading dislocations and interaction with native point defects or dopants during $\mathrm{SiO}_{2}$ passivation and $\mathrm{Zn}$ diffusion. The decorating impurities/native PDs then pin the electrically active dislocation level at a certain value, depending on the degree of decoration. However, our MOVPE $\mathrm{p}+\mathrm{n}$ junctions have been prepared without an additional thermal budget or high temperature treatment; the highest processing step is the sidewall passivation by $\mathrm{ALD}$ of $\mathrm{Al}_{2} \mathrm{O}_{3}$ at a temperature below $150{ }^{\circ} \mathrm{C}$. We believe that this allows Tp measurements to reveal the relatively "pure" nature of the grown-in dislocations, resulting in the "band-like" states behavior of E2. Moreover, the capture cross sections reported in Ref. 33 follow the trend of
E2: the shallower levels correspond with a smaller $\sigma_{\mathrm{n}}$. As a result, based on the low ${ }^{39}$ and the high ${ }^{32,33}$ indium content data, it is concluded that the E2 band corresponds with segments of threading dislocations.

Opposite to electron traps, less data for hole traps related to extended defects in $\operatorname{In}_{\mathrm{x}} \mathrm{Ga}_{1-\mathrm{x}}$ As have been reported; the corresponding activation energy data are summarized in Fig. 11 together with the values for the minority carrier traps $\mathrm{H} 1$ and $\mathrm{H} 2$ found in this work. The level HD1 at $\mathrm{E}_{\mathrm{V}}+0.37 \mathrm{eV}$ has been assigned to $\beta 60^{\circ}$ misfit dislocation in $\mathrm{GaAs}^{35}$ and a band-like state $\mathrm{HD} 3$ at $\mathrm{E}_{\mathrm{V}}+0.7 \mathrm{eV}$ was reported for misfit dislocations in $\mathrm{In}_{0.02} \mathrm{Ga}_{0.98} \mathrm{As}$. ${ }^{7}$ Finally, hole traps related to EDs with unspecified indium content from 0.05 to 0.24 have been reported. ${ }^{36}$ Given this lack of accurate data, no straightforward conclusions can be drawn from Fig. 11. This leaves the door open for different interpretations: first, assuming $\mathrm{HD} 1$ is pinned to the valence band and extrapolating to $\mathrm{H} 2$ (black dashed line) or, HD3 is pinned to the conduction band and can be extrapolated to H2 (blue dash-dot line). Second, for the trap H1, it might be the minority carrier response from the bottom states of the band-like E2, or it can be related to the TD hole traps found in Refs. 36 and 42, which pin it to the conduction band (purple dotted line).

Next to a comparison with literature, one can also rely on the evolution of the magnitude of the DLTS peak height (at sufficiently long Tp) with the EDDs in the different samples. The fact that within the accuracy of the HRXRD analysis, the indium content and residual strain identically across the sample set validate this approach. Comparing the dominant EDs, identified by structural analysis and the peak height for the different electron traps, one can establish a link between the localized states E1 and $\alpha$ dislocations, the band-like states E2 and TD segments and, finally, $\mathrm{H} 2$ and $\beta$ dislocations. Based on Figs. 5 and 6 , and Table I, the following trends can be identified.

The amplitude of E2 is always larger than that of E1, and E1 and E2 coexist in most of the samples, except the low EDDs specimens. The magnitude increases along with the increase of the lattice-mismatch, which indicates that one electron trap should belong to $\alpha 60^{\circ}$ dislocations (ED1) and the other to TD segments (interaction between different $60^{\circ}$

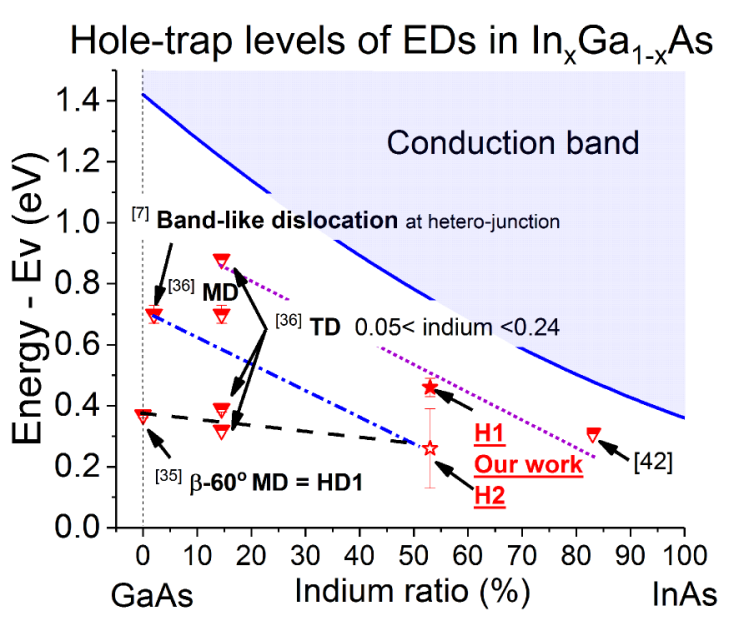

FIG. 11. Literature data for the hole traps in $\operatorname{In}_{x} \mathrm{Ga}_{1-\mathrm{x}} \mathrm{As}$ corresponding to specific extended defects. The data reported here for $\mathrm{H} 1$ and $\mathrm{H} 2$ are also included. 
dislocations). In a simple MD gliding mechanism, if the hetero-nucleation with half loop $60^{\circ} \mathrm{MD}$ and dislocation multiplication are energetically preferable, usually happening in specimens with a high defect density (EDDs $>1 \times 10^{8} \mathrm{~cm}^{-2}$ with a layer thickness of $1 \mu \mathrm{m}),{ }^{51}$ the density of TD segments will be larger than the density of MDs. Besides, if considering similar "localized" states for E1 and more TD segments generated from interaction of $\alpha-\beta$ and $\beta-\beta$ dislocations as well, E1 should be ED1 and E2 corresponds with TD segments.

Furthermore, can $\mathrm{H} 1$ or $\mathrm{H} 2$ belong to $\beta 60^{\circ}$ dislocations (HD1) due to the nature of hole traps? If H1 is HD1, then it is unreasonable that $P_{-} I n 47$ has such a large HD1 peak, without any $\alpha$ dislocations (E1) signal, where AFM shows the $\alpha$ dislocation MD line only. In turn, if $\mathrm{H} 2$ is HD1, the overlapping effect is significant due to the same peak position between $\mathrm{E} 1=\mathrm{ED} 1$ and $\mathrm{H} 2=\mathrm{HD} 1$ at $\mathrm{T}=110 \mathrm{~K}$, which explains why the $\alpha$ dislocation-rich sample (P_In40) shows the E1 signal only and the $\beta$ dislocation-rich sample (G_SRB) shows the H2 peak only in Fig. 6. On the other hand, peak H1 also overlaps with E2 and was found in most samples, except P_In40, so we suggest $\mathrm{H} 1$ can be the minority response of the band-like states E2. However, as mentioned in the beginning, the overlapping and narrow bandgap might complicate the hole trap identification, so a further study for active layers with different indium content is required to further substantiate our interpretation.

In addition to trap identification, an important question to answer is whether the huge change in pre-exponential factor $K_{T}$ for the E2 band-like states can be explained by the potential barrier building up while filling the DOS with increasing $\mathrm{Tp}$. Based on numerical simulations by other groups, in the same range of $\mathrm{Tp}$, a much smaller three orders of magnitude change in $\mathrm{K}_{\mathrm{T}}$ can be derived by applying simulation results on the conventional Arrhenius plot. ${ }^{40,41}$ If this difference is only caused by the exponential capture barrier $\sigma_{n}=\sigma_{\infty} \exp \left(-\delta E_{c / k T}\right)$, it gives an at least nine times bigger capture barrier energy $\left(\delta E_{c}\right)$ in our samples, which seems rather unreasonable. Besides, there are some contradictions with the natures of peak shape of "localized" and "band-like" states: for the low-temperature side of "localized" E1 (Fig. 8), the shoulder of the peaks does not increase along with increasing $\mathrm{Tp}$ when normalized by the amplitude. This can also be observed in localized ED1 of $\operatorname{InGaAs}^{7,9}$ with little explanations; and for "band-like" states, the inverse shift of the peak does not report in any literature before.

One possible interpretation is that the capture cross sections (including the entropy factor) are dependent on electrical states along with the 1D-DOS of dislocation, i.e., these DOS have non-neutral centers (either repulsive or attractive centers), which strongly changes the behavior of energy barrier surrounding dislocations. In the simulation of extended defects with pioneering group IV semiconductors, Schröter et al. ${ }^{5,41,40}$ have suggested that all electrical states in initial empty states are neutral and have same capture cross section. However, considering the configuration of the threading segments of a typical $60^{\circ}$ mixed dislocation in III/V materials, it is possible that the most distorted center could have two types of missing atoms. For example, SFs and pure

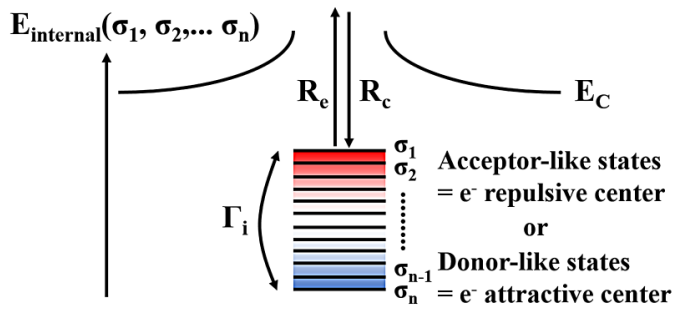

FIG. 12. A schematic graph for band-like states with capture cross section depending on the energy states in the 1D DOS in III/V materials. $\Gamma_{i}$ is the internal equilibrium rate, $\mathrm{R}_{\mathrm{c}}^{-1}$ and $\mathrm{R}_{\mathrm{e}}^{-1}$ are the inverse capture and emission rate, respectively. $\sigma_{1}, 2 \ldots, \mathrm{n}$ represent different capture cross sections inside the band of states, for a typical electron repulsive center $\sigma_{\mathrm{n}}<10^{-16} \mathrm{~cm}^{2}$ and electron attractive center $\sigma_{\mathrm{n}}>10^{-14} \mathrm{~cm}^{2}$.

screws compose with two Shockley partials $\left(30^{\circ} \mathrm{As}_{(\mathrm{g})}\right.$ and $\left.30^{\circ} \mathrm{Ga}_{(\mathrm{g})}\right)$, and the coexistence between the shuffle and glide set. As a result, this distribution of missing group III and group V centers should create both acceptor-like and donorlike states inside the band (an illustrative graph in Fig. 12). It strongly impacts not only the distribution of the internal electric field along the 1D DOS ( $E_{\text {internal }}$ in Fig. 12), which is neglected in modelling of group IV dislocations ${ }^{40,41}$ with mean value of the electric field over the whole structure, but also the factors of external electric field (Poole-Frenkel effect and trap-assisted tunneling) on the 1D DOS. If this configuration of 1D-DOS is true, the internal electric field should have a more significant impact on "band-like" than on "localized" states due to the internal equilibrium time $\Gamma_{\mathrm{i}} \gg$ > inverse capture and emission rate $\mathrm{R}_{\mathrm{c}}^{-1}, \mathrm{R}_{\mathrm{e}}^{-1}$. In the end, the different quasi-static states between the internal built-in energy barrier and external electric field-enhancement changes the nature of "band-like" dislocations in III/V materials.

Finally, a few words should be said about the observed point defect peaks PD1 and PD2. A serious candidate for the grown-in PD in $\mathrm{In}_{\mathrm{x}} \mathrm{Ga}_{1-\mathrm{x}} \mathrm{As}$ is the electron trap labeled EL2, also known as the antisite defect $\mathrm{As}_{\mathrm{G} a / \mathrm{In}}$. The generation of EL2 not only depends on the growth conditions but also on the post-growth treatment. ${ }^{43}$ Available DLTS data (activation energy) for EL2 in n-type $\operatorname{In}_{\mathrm{x}} \mathrm{Ga}_{1-\mathrm{x}} \mathrm{As}$ are collected in Fig. 13, as a function of the indium content. ${ }^{8,34,37,43,49}$

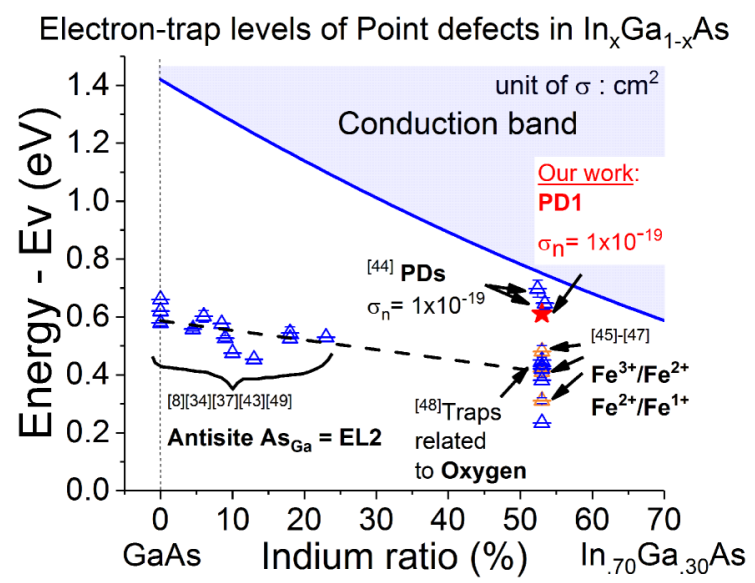

FIG. 13. Literature data for the activation energy of grown-in point defects, behaving as electron traps in $\operatorname{In}_{\mathrm{x}} \mathrm{Ga}_{1-\mathrm{x}}$ As in function of the indium content $\mathrm{x}$. Data for PD1 obtained here are included for comparison. 
Extrapolation to a composition of 53\% indium shows that the possible electron trap position for EL2 is at mid-gap, giving rise to an efficient generation/recombination center. This rules out EL2 as the origin of PD1 and PD2. Other candidates are iron from out-diffusion from the SI-InP substrate and oxygen from MOVPE precursors, respectively. However, both occupy mid-gap levels and behave as electron traps as well. ${ }^{45-48}$

Besides experimental data, one can compare with $a b$ initio calculation results for $\mathrm{In}_{0.53} \mathrm{Ga}_{0.47} \mathrm{As}$ to have an idea about the likely origin of the observed PD levels. Recent Density Functional Theory (DFT) calculations confirm a close to mid-gap position for EL2 at $\mathrm{E}_{\mathrm{C}}-0.43 \mathrm{eV} .{ }^{50}$ On the other hand, an even higher concentration with lower formation energy was predicted for the gallium $\left(\mathrm{V}_{\mathrm{Ga}}\right)$ and indium vacancy $\left(\mathrm{V}_{\text {In }}\right)$ (based on Ga-poor or In-poor growth conditions). An energy level at $\mathrm{E}_{\mathrm{V}}+0.44 \sim 0.45 \mathrm{eV}$, corresponding with the triple/double negative charge state $\left(\mathrm{V}_{\mathrm{Ga} / \mathrm{In}}{ }^{3-/ 2-}\right)$ was predicted. This value is in the neighborhood of the PD2 hole trap level at $\mathrm{E}_{\mathrm{V}}+0.42 \pm 0.01 \mathrm{eV}$ with a typical high $\sigma_{\mathrm{p}}$, which is to be expected from the 3- charge state of the $\mathrm{V}_{\mathrm{Ga}}$ before hole capture. Besides, an electron trap with similar signature has been found in DLTS by other groups. ${ }^{44}$ It appears to be the most likely candidate for level PD1.

If the theoretical prediction for the EL2 level and $\mathrm{V}_{\mathrm{Ga} / \mathrm{In}}{ }^{3-12-}$ in $\mathrm{In}_{0.53} \mathrm{Ga}_{0.47} \mathrm{As}$ is correct, then the following mechanism for dislocation-PD interaction ${ }^{43}$ could be considered, that is, under tensile stress,

$$
\text { Dislocation }+A s_{i} \rightarrow \text { dislocation climb }+V_{G a}
$$

and under compressive stress,

$$
\text { Dislocation }+V_{G a} \rightarrow \text { dislocation climb }+A s_{i} .
$$

Antisites can be produced by the following recombination reaction:

$$
V_{G a}+A s_{i} \rightarrow A s_{G a}
$$

Because EL2 mainly involves reactions $(7)+(8)$, instead of $(6)+(8),{ }^{43}$ EL2 is most likely to appear when the layer is under compressive stress. It can explain the absence of EL2 in low EDDs (EDDs < PDDs) samples, which is under tensile stress only. However, PD2 should be detected in sample P_In47 as well. The reason for its absence might be the immediate recombination of a captured hole by a subsequent electron capture, discussed in the DLTS section.

\section{CONCLUSIONS}

Three deep electron traps, labelled E1, E2, and PD1, and three deep hole traps, labelled H1, H2, and PD2 have been revealed by DLTS in $\operatorname{In}_{0.53} \mathrm{Ga}_{0.47} \mathrm{As} \mathrm{p}+\mathrm{n}$ junctions with well-characterized grown-in extended defects, introduced intentionally from lattice mismatch during MOVPE on SI InP and SI- GaAs substrates. The residual strain is negligible in the active $\mathrm{In}_{0.53} \mathrm{Ga}_{0.47}$ As layer so that the electrical states of the extended and point defects can be analyzed under fixed bandgap and intrinsic doping density. From a thorough analysis, the E1 electron trap, with "localized states" energy $\mathrm{E}_{\mathrm{C}}-0.17 \pm 0.03 \mathrm{eV}$, was identified as $\alpha 60^{\circ}$ misfit dislocation. E2, with "band-like states" energy levels, ranging from $\mathrm{E}_{\mathrm{C}}-0.17 \pm 0.01$ to $\mathrm{E}_{\mathrm{C}}-0.39 \pm 0.04 \mathrm{eV}$, has been assigned to threading dislocation segments (interaction between both $60^{\circ}$ misfit dislocations). The coexistence of acceptor-like and donor-like states in the 1D DOS of III-V materials has been proposed to explain the high variation of the pre-exponential factor $\mathrm{K}_{\mathrm{T}}$ magnitude in $\mathrm{E} 2$ when changing the filling pulse time. PD2, a hole attractive point defect with activation energy $\mathrm{E}_{\mathrm{V}}+0.42 \pm 0.01 \mathrm{eV}$, is possibly related to $\mathrm{V}_{\mathrm{Ga} / \mathrm{In}}{ }^{3-/ 2-}$. Finally, the hole trap $\mathrm{H} 2$ at $\mathrm{E}_{\mathrm{V}}+0.26 \pm$ $0.13 \mathrm{eV}$ can be related with $\beta 60^{\circ}$ misfit dislocations.

${ }^{1}$ K. Nozawa and Y. Horikoshi, Jpn. J. Appl. Phys. 30, L668 (1991).

${ }^{2}$ C. Merckling, N. Waldron, S. Jiang, W. Guo, O. Richard et al., J. Appl. Phys. 114, 033708 (2013).

${ }^{3}$ S. H. Kim, Y. Ikku, M. Yokoyama, R. Nakane et al., Appl. Phys. Lett. 105, 043504 (2014).

${ }^{4}$ W. Schröter, Inst. Phys. Conf. Ser. 46, 114-127 (1979).

${ }^{5}$ W. Schröter, J. Kronewitz, U. Gnauert, F. Riedel, and M. Seibt, Phys. Rev. B 52, 13726 (1995).

${ }^{6}$ W. Schröter, V. Kveder, M. Seibt, H. Ewe et al., Mater. Sci. Eng. B 72(2-3), 15, 80-86 (2000).

${ }^{7}$ O. Yastrubchak, T. Wosiński, A. Mąkosa, T. Figielski, and A. L. Tóth, Phys. B: Condens. Matter 308-310, 757-760 (2001).

${ }^{8}$ Ł. Gelczuk, M. Dąbrowska-Szata, and G. Jóźwiak, Mater. Sci. 23(3), 625-641 (2005).

${ }^{9}$ Ł. Gelczuk, M. Dąbrowska-Szata, G. Jóźwiak, and D. Radziewicz, Phys. B Condens. Matter 388(1-2), 195-199 (2007).

${ }^{10}$ E. Simoen, G. Eneman, M. Bargallo Gonzalez, D. KobayashiElectrochen et al., J. Electrochen. Soc. 158(5), R27-R36 (2011).

${ }^{11}$ K. H. Chang, R. Gilbala, and D. J. Srolovitz, J. Appl. Phys 67, 4093 (1990).

${ }^{12}$ R. Chierchia, T. Böttcher, S. Figge, M. Diesselberg et al., Phys. Status Solidi 228, 403-406 (2001).

${ }^{13}$ M. A. Moram and M. E. Vickers, Prog. Phys. 72, 036502 (2009).

${ }^{14}$ A. D. Kurtz, S. A. Kulin, and B. L. Averbach, Phys. Rev. 101, 1285 (1956).

${ }^{15}$ Y. Zohta and M. O. Watanabe, J. Appl. Phys. 53, 1809-1811 (1982).

${ }^{16}$ M. S. Abrahams, J. Blanc, and C. J. Buiocchi, Appl. Phys. Lett. 21, 185 (1972).

${ }^{17}$ J. te Nijenhuis et al., J. Phys. D: Appl. Phys. 29, 2961 (1996).

${ }^{18}$ H. Alexander, J. Phys. Colloques 40(C6), C6-1-C6-6 (1979).

${ }^{19}$ P. M. J. Marée, J. C. Barbour, and J. F. van der Veen, J. Appl. Phys. 62, 4413 (1987).

${ }^{20}$ R. Jones, S. Öberg, and S. Marklund, Philos. Mag. B 43, 839-852 (1981).

${ }^{21}$ J. Narayan and S. Sharan, Mater. Sci. Eng. B 10, 261-267 (1991).

${ }^{22}$ C. Ferrari, L. Lazzarini, G. Salviati et al., MRS Online Proc. Library Arch. 578 (2011).

${ }^{23}$ G. Salviati, C. Ferraria, L. Lazzarinia, L. Nasi et al., Appl. Surf. Sci. 188, 36-48 (2002).

${ }^{24}$ J.-M. Chauveau, Y. Androussi, A. Lefebvre, and J. Di Persio, J. Appl. Phys. 93, 4219 (2003).

${ }^{25}$ P. Kidd, D. J. Dunstan, H. G. Colson, M. A. Louren, A. Sacedón et al., J. Cryst. Growth 169, 649-659 (1996).

${ }^{26}$ J. A. Olsen, E. L. Hu, S. R. Lee, I. J. Fritz, A. J. Howard, B. E. Hammons, and J. Y. Tsao, J. Appl. Phys. 79, 3578 (1996).

${ }^{27}$ S. K. Choi, M. Mihara, and T. Ninomiya, Jpn. J. Appl. Phys. 16(5), 737 (1977).

${ }^{28}$ P. Omling, L. Samuelson, and H. G. Grimmeiss, J. Appl. Phys. 54, 5117 (1983).

${ }^{29}$ W. Schröter and H. Cerva, Solid State Phenomena 85-86, 67-144 (2002).

${ }^{30}$ D. V. Lang, J. Appl. Phys. 45, 3023 (1974).

${ }^{31}$ P. N. Grillot and S. A. Ringel, J. Appl. Phys. 77, 3248 (1995).

${ }^{32}$ M. Ogura, M. Mizuta, K. Onaka, and H. Kukimoto, Jpn. J. Appl. Phys. 22, 1502 (1983).

${ }^{33}$ D. Pogany, F. Ducroquet, S. Ababou, and G. Bremond, J. Electrochem. Soc. 140, 560-563 (1993).

${ }^{34}$ V. Ya. Prints, S. A. Kulagin, and V. I. Major, Soviet Physics Semiconductors, 21(12), 1292-1295 (1987).

${ }^{35}$ T. Wosiński and T. Figielski, Acta Phys. Polonica A 83, 51-58 (1993). 
${ }^{36}$ A. Y. Du, M. F. Li, T. C. Chong, S. J. Xu, Z. Zhang, and D. Pyu, Thin Solid Films 311(1-2), 7-14 (1997).

${ }^{37}$ G. P. Watson and D. G. Ast, J. Appl. Phys. 71, 3399 (1992).

${ }^{38}$ Y. Uchida, H. Kakibayashi, and S. Goto, J. Appl. Phys. 74, 6720 (1993).

${ }^{39}$ D. Pal, E. Gombia, R. Mosca, A. Bosacchi, and S. Franchi, J. Appl. Phys. 84, 2965 (1998).

${ }^{40}$ W. Schröter, H. Hedemann, V. Kveder, and F. Riedel, J. Phys. Condens. Matter 14, 13047 (2002).

${ }^{41}$ H. Hedemann and W. Schröter, J. Phys. III France 7, 1389-1398 (1997).

${ }^{42}$ N. Avishan, thesis, The Middle East Technical University, 2016.

${ }^{43}$ A. C. Irvine and D. W. Palmer, Phys. Rev. Lett. 68(14), 2168-2171 (1992).

${ }^{44}$ A. E. Kowalczyk, L. Ornoch, J. Muszalski, and J. Kaniewski, Opt. Appl. XXXV(3), 457-463 (2005)
${ }^{45}$ G. Guillot et al., Semicond. Sci. Technol. 5, 391 (1990); Defect Control in Semiconductors, edited by K. Sumino (North-Holland, 1990), pp. 1027-1030.

${ }^{46}$ Z. Chen, T. Wolf, W. Korb, and D. Bimberg, J. Appl. Phys. 64, 4574 (1988).

${ }^{47}$ M. Sugawara, M. Kondo, T. Takanohashi, and K. Nakajima, Appl. Phys. Lett. 51, 834 (1987).

${ }^{48}$ S. Loualiche, A. Gauneau, A. Le Corre, D. Lecrosnier, and H. L'Haridon, Appl. Phys. Lett. 51, 1361 (1987).

${ }^{49}$ L. Panepinto, U. Zeimer, W. Seifert, M. Seibt, F. Bugge, M. Weyers, and W. Schröter, Mater. Sci. Eng. B 42, 77-81 (1996).

${ }^{50}$ J. Wang, B. Lukose, M. O. Thompson, and P. Clancy, J. Appl. Phys. 121, 045106 (2017).

${ }^{51}$ G. Wang, R. Loo, E. Simoen, and L. Souriau, Appl. Phys. Lett. 94, 102115 (2009). 